\title{
Neuronal and synaptic morphological alterations in the hippocampus of cannabinoid receptor type 1 knockout mice
}

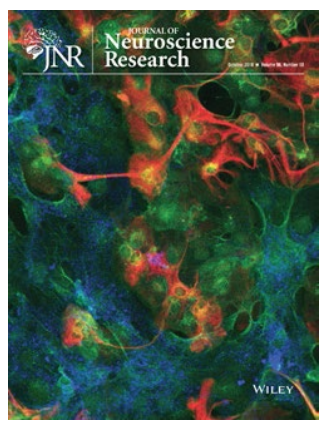

\author{
Delia Soriano $^{1,2}$ (D) | Marina Vacotto ${ }^{2}$ (D) | Alicia Brusco ${ }^{1,2}$ (D) | Laura Caltana ${ }^{1,2}$ (ID
}

\author{
${ }^{1}$ Universidad de Buenos Aires. Facultad \\ de Medicina. $1^{\circ}$ Unidad Académica del \\ Departamento de Histología, Embriología, \\ Biología Celular y Genética. Buenos Aires. \\ Argentina., Buenos Aires, Argentina \\ ${ }^{2}$ Instituto de Biología Celular y Neurociencia \\ Prof. E. De Robertis (IBCN), CONICET- \\ Universidad de Buenos Aires, Buenos Aires, \\ Argentina

\section{Correspondence} \\ Laura Caltana, Instituto de Biología Celular \\ y Neurociencia, Facultad de Medicina, \\ Universidad de Buenos Aires, Ciudad \\ Autónoma de Buenos Aires (1121), Paraguay \\ 2155, $3^{\circ}$ Piso, Buenos Aires, Argentina. \\ Email: lauracaltana@gmail.com

\section{Funding information} \\ Agencia Nacional de Promoción Científica \\ y Tecnológica (ANPCyT), Grant/Award \\ Number: PICT 2016-2240 and PICT 2017- \\ 0610; Consejo Nacional de Investigaciones \\ Científicas y Técnicas, Grant/Award \\ Number: PIP CONICET 00142
}

\begin{abstract}
Cannabinoid receptor type 1 (CB1R) modulates synaptic activity and is widely distributed in brain areas such as the hippocampus, cerebellum, cerebral cortex, and striatum, among others. CB1R is involved in processes such as memory, learning, motor coordination, and mood. Genetic deletion of CB1R causes behavioral alterations. In this work, we evaluated neuronal morphology and synaptic structure in the hippocampus of adult male CB1R knockout mice $\left(\mathrm{CB} \mathrm{R}^{-1-}\right)$. Morphological changes in the $\mathrm{CB}_{1} \mathrm{R}^{-/-}$hippocampus evidenced a decrease in the expression of cytoskeletal proteins neurofilaments $160 \mathrm{KDa}$, neurofilaments $200 \mathrm{KDa}$, and microtubule-associated protein 2. CA1 neurons showed decreased arborization and changes in synaptic structure such as lower thickness of postsynaptic density and a reduction in synaptophysin levels. Results obtained in the present work provide evidence of the participation of CB1R in the establishment of neuronal structure and networks that could have an important role in neuronal plasticity. In addition, these changes observed in $\mathrm{CB}_{1} \mathrm{R}^{-/-}$could be correlated with behavioral alterations reported.
\end{abstract}

\section{KEYWORDS}

cannabinoid receptor type 1, cannabinoid system, RRID:AB_477523, RRID:AB_477193,

RRID:AB_477261, RRID:AB_477257, RRID:AB_143162, RRID:AB_476738,

RRID:AB_10015282, RRID:AB_2340770, neuronal plasticity, synapse

\section{1 | INTRODUCTION}

The endocannabinoid system, which has been conserved evolutionarily from plants to vertebrates (Elphick \& Egertová, 2005; Solymosi \& Köfalvi, 2017), modulates synaptic transmission and consists of cannabinoid receptors type 1 (CB1R) and type 2 (CB2R), its endogenous ligands (anandamide and 2-arachidonoylglycerol) and enzymes involved in its metabolism (Lambert \& Fowler, 2005).

CB1R is widely expressed in the central nervous system in vertebrates, both in neurons and glial cells (Facchinetti, Del Giudice, Furegato, Passarotto, \& Leon, 2003; Metna-Laurent \& Marsicano, 2015; Molina-Holgado et al., 2002), mainly in the cerebral cortex, cerebellum, hippocampus, basal ganglia, striatum, and amygdala ( $\mathrm{Hu}$

\footnotetext{
Abbreviations: CB1R, cannabinoid receptor type 1; CB1R $\mathrm{R}^{-/-}, \mathrm{CB} 1 \mathrm{R}$ knockout mice;

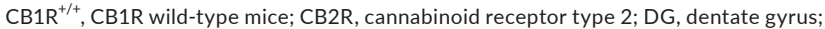
MAP2, microtubule-associated protein 2; NF160, neurofilaments 160 KDa; NF200, neurofilaments $200 \mathrm{KDa}$; PB, phosphate buffer; SD, standard deviation; Syn, synaptophysin; WB, Western blot.

Edited by Hadley Bergstrom. Reviewed by Ozge Gunduz-Cinar, Javier Palazuelos, and Erica Holliday.
} 
\& Mackie, 2015). CB1R is one of the most abundant G protein-coupled receptors in the central nervous system and is mainly presynaptically located in axonal terminals.

In mammals, CB1R participates in the regulation of motor coordination, anxiety, memory, and appetite (Marsicano \& Lafenetre 2009). Activation of CB1R modulates cell excitability, neurotransmitter release, transient or permanent synaptic transmission, thus participating in short- and long-term plasticity by different signaling pathways (Castillo, Younts, Chávez, \& Hashimotodani, 2012; Ligresti, De Petrocellis, \& Di Marzo, 2016; Xu \& Chen, 2015). CB1R also modulates voltage-dependent ion channels and inhibits voltage-gated $\mathrm{Ca}^{2+}$ channels ( $\mathrm{N}$ - and $\mathrm{P} / \mathrm{Q}$-type) and activates rectifying $\mathrm{K}$ channels (Ligresti et al., 2016).

The hippocampus has demonstrated an essential role in cognitive and emotional functions, involving plasticity process such as structural and functional changes and generation of new neurons (Fanselow \& Dong, 2010; Gould, 2009). The hippocampus has behavioral, anatomical, and functional segmentation into separate structural; dorsal hippocampus is involved in learning, memory, and exploration, while the ventral hippocampus modulates emotional and affective processes (Fanselow \& Dong, 2010). CB1R is highly expressed in hippocampus and mediates learning and memory functions (Marsicano \& Lafenetre, 2009), regulates mood states (Marco $\&$ Viveros, 2009) and synaptic changes associated (Alger, 2009).

Alteration in CB1R signaling produced changes in emotional behavior showing anhedonic state (Burokas et al., 2014; SanchisSegura, Cline, Marsicano, Lutz, \& Spanagel, 2004), impaired extinction of aversive memory (Marsicano et al., 2002; Martin, Ledent, Parmentier, Maldonado, \& Valverde, 2002), and an increase in the conditioned fear responses (Jacob, Marsch, Marsicano, Lutz, \& Wotjak, 2012). Several studies have demonstrated an anxiogenic behavior in CB1R knockout mice $\left(\mathrm{CB}^{-\mathrm{R}^{-/}}\right)$or upon pharmacological blockade of CB1R under normal conditions (Bowers \& Ressler, 2016; Martin et al., 2002). Hypothalamic-pituitary-adrenal axis dysregulation has been observed in $\mathrm{CB}^{-/ \mathrm{R}^{-/}}$(Barna, Zelena, Arszovszki, \& Ledent, 2004), anxiety-like behavior similar to that detected in naive mice exposed to stress conditions (Hill, Hillard, \& McEwen, 2011). In addition, $\mathrm{CB}_{1 \mathrm{R}^{-/-}}$presents alterations in long-term synaptic plasticity in corticolimbic structures such as amygdala and hippocampus (Bohme, Laville, Ledent, Parmentier, \& Imperato, 2000; Jacob et al., 2012; Marsicano et al., 2002; Monory, Polack, Remus, Lutz, \& Korte, 2015) and an increase in serotonin level in prefrontal cortex in normal conditions, but these decrease after fluoxetine is administered (Aso et al., 2009; Ferreira et al., 2012). As functional alterations found in $\mathrm{CB}_{1} \mathrm{R}^{-/-}$correlate with a decrease in $\mathrm{CB} 1 \mathrm{R}$ receptor expression in animal models of depression (Hill et al., 2008), $\mathrm{CB}_{1 \mathrm{R}^{-/-}}$has been postulated as a model of depression (Valverde \&Torrens, 2012). Hay and collaborators indicate that disruption of conserved regulatory sequence (ECR1) in cnr1, that contained a polymorphism, reduced CB1R expression in the hippocampus and decreased anxiety-related behaviors (Hay et al., 2019).

CB1R is implicated in the process of long-term plasticity associated with spatial learning and memory. Deletion of CB1R can

\section{Significance}

Cannabinoid receptor type 1 (CB1R) is expressed in the central nervous system, mainly in cerebral cortex, hippocampus, cerebellum, and striatum at presynaptic level. CB1R plays a modulatory role in synaptic activity regulating the neurotransmitter release. The blockade of CB1R, by genetic or pharmacological approach, induces neuronal plasticity alterations. Here, we demonstrated that genetic ablation of CB1R induces morphological alterations in neuronal cytoskeleton and synapse, which correlates with morphological alterations observed in chronic exposure to CB1R agonist. These data support that CB1R participates also in the neuronal feature development.

result in increased long-term potentiation in hippocampus (Bohme et al., 2000; Jacob et al., 2012), but contraries' alteration has been observed in spatial memory in these mice (Albayram et al., 2011; Jacob et al., 2012; Lin et al., 2011; Mikics et al., 2006). In addition, treatment with CB1R antagonist induces increased long-term potentiation (Hoffman et al., 2007; Slanina, Roberto, \& Schweitzer, 2005) and enhanced spatial memory (de Oliveira, Pasqualini, Diehl, Molina, \& Quillfeldt, 2008; Jacob et al., 2012; Lichtman, 2000; Lin et al., 2011; Reich, Mohammadi, \& Alger, 2008; Sink et al., 2010). Also, cannabis users present memory deficit (Ilan, Smith, \& Gevins, 2004; Schweinsburg, Brown, \& Tapert, 2008; Solowij et al. 2002) and this could correlate with reduction in the expression of CB1R (Hirvonen et al., 2012; Rotter et al., 2013; Villares, 2007) and smaller volume of the hippocampus (Lorenzetti, Chye, Silva, Solowij, \& Roberts, 2019; Schacht, Hutchison, \& Filbey, 2012).

The expression levels of the CB1R in humans are associated with different polymorphisms in the cnr1 gene (Zhang et al., 2004), many of them have been correlated with psychiatric disorders (Hillard, Weinlander, \& Stuhr, 2012) such as anxiety, depression, and psychosis (Juhasz et al., 2009; Lazary et al., 2009; Suárez-Pinilla et al., 2015), and with alteration in learning and memory (Fairfield et al., 2018; Ruiz-Contreras et al., 2011, 2014).

Endocannabinoid signaling participates in the development of thalamocortical projections, and CB1R ligands disrupt its normal formation (Itami et al., 2016). CB1 $\mathrm{R}^{-/-}$mice and pyramidal cell-specific conditional mutant mice develop deficits in neuronal progenitor proliferation and axon fasciculation. Moreover, pharmacological blockade of CB1R during development induces axonal disruption (Mulder et al., 2008; Tortoriello et al., 2014; Watson, Chambers, Hobbs, Doherty, \& Graham, 2008) and impairs dendritic elongation (Tapia et al., 2017). In utero blockade of CB1R by CB1R siRNA electroporation alters neuronal migration during cortical development, and increases seizures induced by convulsant pentylenetetrazol (Díaz-Alonso et al., 2017). In vitro studies of cortical neurons have shown that the activation of the CB1R produces a decrease in the axonal diameter and in the growth of neurites, product of changes 
in dynamics of the neuronal cytoskeleton (Njoo, Agarwal, Lutz, \& Kuner, 2015; Tortoriello et al., 2014). Chronic treatment with CB1R agonist during adolescence causes a deterioration in spatial memory in adulthood, which is correlated with the decrease in the expression of pre- and postsynaptic components, less arborization, and a lower number of spines observed in granular neurons of the hippocampus (Rubino et al., 2009). Moreover, chronic exposure to the nonselective cannabinoid agonist, WIN55,212-2, in the adult induces a decrease in MAP2 expression in the CA1 area of the hippocampus (Lawston, Borella, Robinson, \& Whitaker-Azmitia, 2000) and a decrease in the number of spines in neurons (Candelaria-Cook \& Hamilton, 2014).

There are significant associations between cnr1 polymorphisms and changes in specific brain structure such as reduced caudate nucleus and thalamus volumes and white matter (Suárez-Pinilla et al., 2015). Also, cnr1 polymorphisms may predispose smaller hippocampal volume after heavy cannabis use (Lorenzetti et al., 2019; Schacht et al., 2012). These morphological brain abnormalities are consistent with the link to some psychiatric disorders. A recent stereological postmortem study in depression and schizophrenia subjects indicates that the volume and number of cells in different areas of hippocampus are reduced (Chen et al., 2019).

As changes in behavior are usually accompanied by morphological changes in neurons and synapses in related areas such as the hippocampus and the amygdala, this work evaluated neuronal morphology, neuronal cytoskeleton, and synaptic structure in the hippocampus using $\mathrm{CB}_{1} \mathrm{R}^{-/-}$mice. The purpose of this work is to describe the neuronal histological changes that are produced by the deficiency of CB1R that could explain the alterations in long-term synaptic plasticity, the behavioral changes described in $\mathrm{CB}_{1 \mathrm{R}^{-/-}}$mice.

\section{2 | METHODS}

\section{1 | Animals}

Fifteen male $\mathrm{CD} 1 \mathrm{CB} 1 \mathrm{R}$ wild-type $\left(\mathrm{CB} 1 \mathrm{R}^{+/+}\right)$and 15 male $\mathrm{CB} 1 \mathrm{R}$ knockout mice $\left(\mathrm{CB} 1 \mathrm{R}^{-/-}\right)$were used in this study. $\mathrm{CB}_{1 \mathrm{R}^{-/-}}$mice were generated by disruption of the cnr1 gene as previously described by Ledent et al. (1999) and kindly donated by Prof. Dr. György M. Nagy (Hungarian Academy of Science and Semmelweis University, Budapest, Hungary). Heterozygote-heterozygote $\left(\mathrm{CB} 1 \mathrm{R}^{+/-}\right.$) mating produced $\mathrm{CB}_{1} \mathrm{R}^{+/+}$and $\mathrm{CB} 1 \mathrm{R}^{-/-}$littermates. At postnatal day 21, male offspring wereweaned and obtain tail samples forgenotyping. Animals were genotyped by polymerase chain reaction $(\mathrm{PCR})$ technique using primers "CB1" (forward: 5' CATCATCACAGATTTCTATGTAC; WT reverse: 5' GAGGTGCCAGGAGGGAACC) and "Neo" (mutant forward: 5' GCAGGATCTCCTGTCATCTACC; mutant reverse: 5' GATGCTCTTCGTCCAGATCATCC). CB1R ${ }^{+/+}$and CB1R ${ }^{-/-}$amplicons are $\sim 360$ base pairs and $\sim 250$ base pairs, respectively (See Figure S1). After genotyping, 60-day-old male mice were chosen by simple random selection from litters. Animals were housed five or six male offspring of each litter per cage, in a humidity- and temperature-controlled environment (12 hr/12 hr light/dark cycle), with free access to standard laboratory rodent food and water. Animal treatments were in accordance with CICUAL protocols (Institutional Committee for the Care and Use of Laboratory Animals, School of Medicine, University of Buenos Aires, RES (CD) 2198/2015).

\section{2 | Immunohistochemistry}

Five $\mathrm{CB} 1 \mathrm{R}^{+/+}$mice and five $\mathrm{CB} 1 \mathrm{R}^{-/-}$mice were fixed by intracardiac perfusion with $4 \%(\mathrm{w} / \mathrm{v})$ paraformaldehyde in $0.1 \mathrm{M}$ phosphate buffer (PB) $\mathrm{pH} 7.4$ and postfixed for $4 \mathrm{hr}$ in the same solution. Coronal sections of the brains were cut with a vibratome $(40-\mu \mathrm{m}$ thick) and stored in $50 \%(\mathrm{v} / \mathrm{v})$ glycerol solution at $-20^{\circ} \mathrm{C}$ until use. Coronal serial sections containing hippocampus were selected from five different mice of each group.

Immunohistochemistry was performed with following primary antibodies: mouse anti-Synaptophysin (Syn, 1:1,000, Sigma-Aldrich, St Louis, MO, USA, Cat\# S5768, RRID:AB_477523); mouse anti-microtubule-associated protein 2 (MAP2, 1:1,000, Sigma-Aldrich, Cat\# M4403, RRID:AB_477193); mouse anti-neurofilament $160 \mathrm{kDa}$ (NF160, 1:1,000, Sigma-Aldrich, Cat\# N2787, RRID:AB_477261); mouse anti-neurofilament 200 kDa (NF200, 1:1,000, Sigma-Aldrich, Cat\# N0142, RRID:AB_477257). The same antibodies against Syn, NF160, NF200, and MAP2 were used in previous studies from our laboratory (Caltana, Saez, Aronne, \& Brusco, 2015; Evrard et al., 2006; Tagliaferro et al., 2006).

For immunofluorescent labeling, after incubating with primary antibodies, brain serial slices (four to six slices per animal) were washed in phosphate saline buffer and incubated for $4 \mathrm{hr}$ with fluorescent secondary antibodies anti-mouse IgG Alexa 568 (1:500, Invitrogen, Carlsbad, CA, USA, RRID:AB_143162). Sections were later counterstained with Hoechst $33342(2 \mu \mathrm{g} / \mathrm{ml}$, Sigma-Aldrich) to label nuclei and coverslipped with $70 \%(\mathrm{v} / \mathrm{v})$ glycerol mounting medium.

Images were acquired on an Axiolab epifluorescence microscope (Carl Zeiss, Göttingen, Germany) equipped with a Q-Color3 CCD camera (Olympus, Tokyo, Japan). Counting and morphometry were performed using ImageJ (NIH, https://imagej.net, RRID:SCR_003070) software. Brain areas analyzed were the stratum radiatum of CA1 and CA2, CA3 and the molecular layer of the dentate gyrus (DG), those areas were identified and defined according to the Mouse Brain in Stereotaxic Coordinates Atlas (Franklin \& Paxinos, 2007). In accordance with Kohara et al. (2014), Chevaleyre and Siegelbaum (2010) and Botcher, Falck, Thomson, and Mercer (2014), we visually identified the CA2 area as the region with the thickest somatic layer located between CA3, characterized by its distinct mossy fiber terminal layer, and CA1, characterized by its compact cell body layer.

In order to ensure objectivity, for each set of experiments, all measurements were performed on coded slides, in blind conditions, by two observers (DS and LRC). Measurements of both groups of $\mathrm{CB}_{1} \mathrm{R}^{+/+}$and $\mathrm{CB} 1 \mathrm{R}^{-/-}$sections were carried out in standardized conditions (at the same session, in the same day, by the same observer). In each tissue section, each microscopic field was selected within 
the limits of each anatomical area of interest to be morphometrically analyzed.

In order to evaluate MAP2, NF160+, and NF200+ fibers, the total area of the immunolabeled fibers was related to the total area of the corresponding microscopic field ( $20 \times$ primary magnification), rendering a relative area parameter.

Optical intensity of Syn expression was analyzed in the stratum radiatum of CA1 and CA2, CA3 and the molecular layer of the DG. Optical intensity was analyzed quantitatively using an image analysis system (ImageJ). Color images were acquired for each hippocampal area by a digital camera connected to the fluorescent microscope. The images were transferred to black-white images and mean light transmission was measured on a scale of 0 to 256 relative units. This measurement was repeated 15 times $\left(50 \mu \mathrm{m}^{2}\right)$ on each image and averaged. To normalize the variations in immunostaining strength between the slides, the intensity of each individual layer was divided by the intensity of the corpus callosum in each section, which was selected for background levels of immunoreactivity because of the absence of axon terminals (Jung et al., 2009).

\section{3 | Electron microscopy}

Five $\mathrm{CB}_{1} \mathrm{R}^{+/+}$mice and five $\mathrm{CB} 1 \mathrm{R}^{-/-}$mice were fixed by intracardiac perfusion with $4 \%(\mathrm{w} / \mathrm{v})$ paraformaldehyde and $0.25 \%(\mathrm{v} / \mathrm{v})$ glutaraldehyde in PB (Tagliaferro et al., 2006). Dissected sections of $1 \mathrm{~mm}^{3}$ corresponding to CA1 area of hippocampus were postfixed in $1 \%(\mathrm{w} / \mathrm{v})$ osmium tetroxide in the same $\mathrm{PB}$ for $30 \mathrm{~min}$ After dehydration in ethanol gradient, tissues were contrasted with $5 \%(\mathrm{w} / \mathrm{v})$ uranyl acetate and then embedded in Durcupan (Fluka AG, Chemische Fabrik, Buchs SG, Switzerland). After sections were embedded in Durcupan, $1-\mu \mathrm{m}$ slices were obtained and toluidine blue stained, to select similar areas of CA1 stratum radiatum. Then ultrathin sections $(50 \mathrm{~nm})$ were obtained and stained with lead citrate (Reynolds, 1963). Images were acquired on a Zeiss 109 transmission electron microscope (TEM) (Carl Zeiss, Oberkochen, Germany) and photographed with a GATAN CCD camera (Pleasanton, CA, USA).

For electron microscopy images, synapse number per $100 \mu \mathrm{m}^{2}$ was measured in CA1 stratum radiatum $\left(\mathrm{CB} 1 \mathrm{R}^{+/+}: 49\right.$ areas, $\mathrm{CB} 1 \mathrm{R}^{-/-}$: 45 areas). For synapse morphology, the number of synaptic vesicles, synaptic curvature (ratio of the synaptic length in the synaptic gap and the distance between the synaptic limits), and the thickness of the postsynaptic density $\left(\mathrm{CB} 1 \mathrm{R}^{+/+}: 121\right.$ synaptic terminals and $\mathrm{CB} \mathrm{R}^{-/-}: 122$ synaptic terminals) were measured using Image J.

\section{4 | Golgi stain}

Five $\mathrm{CB} 1 \mathrm{R}^{+/+}$mice and five $\mathrm{CB} 1 \mathrm{R}^{-/-}$mice brains were dissected and fixed with $4 \%(\mathrm{w} / \mathrm{v})$ paraformaldehyde during $24 \mathrm{hr}$. They were later immersed in $3 \%(\mathrm{w} / \mathrm{v})$ potassium dichromate solution (Sigma-Aldrich) for 3 days in the dark, and then transferred into $2 \%(\mathrm{w} / \mathrm{v})$ silver nitrate solution (Sigma-Aldrich) for 1 day in the dark at room temperature (modified from Bayram-Weston, Olsen, Harrison, Dunnett, \& Brooks, 2016).

At the end of this time, $100-\mu \mathrm{m}$ thick sections were cut with a vibratome in distilled water, and sections were collected in $0.3 \%$ $(w / v)$ gelatin solution. Finally, sections were mounted on slides, dehydrated by air-drying and coverslipped using Canada Balsam-type mounting medium.

Golgi-stained brain slices were analyzed using an inverted microscope DSU OlympusIX83. Proximal neuronal complexity and primary dendrites' number of representative pyramidal neurons (10-12 slices per animal, four tor five neurons per slice, from three animals per phenotype) from hippocampal CA1 region were analyzed as previously described (Sholl, 1953; Spilker et al., 2016). Sholl analysis was performed by analyzing dendritic branching, number of apical and basal dendrites, and dendritic diameter. To determine spine density, the number of spines on segments of at least $100 \mu \mathrm{m}$ of dendritic length/neuron was counted. The number of spines was measured in the first $100 \mu \mathrm{m}$ from the first branching point (secondary dendrites) of the principal dendrite. Dendritic spine were classified according their morphology in mature shaped spines, which included Type I (stubby) and Type II (mushroom) and Type III (immature-shaped thin) (Ferreras et al., 2017). For quantitative analysis of their branching patterns and spine density NeuroJ plugin ImageJ software and Cell target software were used (Garcia-Segura \& Perez-Marquez, 2014).

\subsection{Western blot (WB)}

Five $\mathrm{CB} 1 \mathrm{R}^{+/+}$mice and five $\mathrm{CB} 1 \mathrm{R}^{-/-}$mice were anesthetized with a solution containing ketamine/xylazine $(100 \mu \mathrm{g} / \mathrm{g} ; 10 \mu \mathrm{g} / \mathrm{g}$ dissolved in saline solution) and decapitated, then the brain and hippocampi were dissected. The samples were homogenized in RIPA homogenization buffer (PMSF $1 \mathrm{mM}$, EDTA $1 \mathrm{mM}, \mathrm{Na}_{3} \mathrm{VO}_{4} 1 \mathrm{mM}, \mathrm{NaF} 10 \mathrm{mM}$ ) with protease inhibitors and centrifuged at $14.000 \mathrm{rpm}$ for $10 \mathrm{~min}$ at $4^{\circ} \mathrm{C}$, after which the supernatant was collected. Samples $(50 \mu \mathrm{g}$ protein) were filled into an $8 \%$ SDS-PAGE gel; the proteins were divided by electrophoresis and then tranferred to nitrocellulose membranes, which were then incubated with primary antibodies (Guadagnoli, Caltana, Vacotto, Gironacci, \& Brusco, 2016). The antibodies used for immunoblot were as follows: mouse anti-Syn (1:1,000, Sigma); mouse anti-MAP2 (1:2,000, Sigma); mouse anti-NF160 (1:1,000, Sigma); mouse anti-NF200 (1:1,000, Sigma); rabbit anti-actin (1:1,000, Sigma-Aldrich Cat\# A5060, RRID:AB_476738) (Figure S2). After being washed, the blot was incubated with a 1:2,000 dilution of a peroxidase-coupled donkey anti-rabbit polyclonal antiserum (Jackson ImmunoResearch Laboratories Inc. Cat\#711-035-152, RRID:AB_10015282) or peroxidase-coupled donkey anti-mouse polyclonal antiserum (Jackson ImmunoResearch Laboratories Inc. Cat\# 715-035-150, RRID:AB_2340770) for $1 \mathrm{hr}$ at room temperature. Finally, bound enzymatic activity was detected by the enhanced chemiluminescence system (ECL+) from Amersham. 


\section{6 | Statistical analysis}

Sixty-day-old $\mathrm{CB}_{1} \mathrm{R}^{+/+}$and $\mathrm{CB}_{1} \mathrm{R}^{-/-}$male mice were randomly selected from litters after genotyping. The number of animals ( $n$ ) was calculated according to Arifin and Zahiruddin (2017) following the 3Rs rule (Russell \& Burch, 1959). For immunohistochemistry, three separate experiments were run for each immunostaining study. Individual experiments were composed of 6 to 10 coronal serial sections of each animal from each group. Three to five fields were measured from each hippocampus in each coronal section of each animal by stereological analysis method using ImageJ (https://imagej.nih. gov/ij/plugins/grid.html).

For WB, three separate experiments were run for each immunostaining study. Individual experiments were composed of five animals from each group.

Statistical analysis was performed using GraphPad Prism 4 (GraphPad Software Inc., La Jolla, CA, USA). In immunostaining, $W B$, and electron microscopy images quantification, statistical significance was assessed by unpaired student's $t$ test to compare the means of $\mathrm{CB}_{1} \mathrm{R}^{+/+}$and $\mathrm{CB} 1 \mathrm{R}^{-/-}$mice. The same analysis was performed in dendritic diameter, dendritic branching, and number of spines in Golgi stain to compare the means of $\mathrm{CB}_{1} \mathrm{R}^{+/+}$and $\mathrm{CB} 1 \mathrm{R}^{-/-}$ mice. In the case of dendritic intersections in Golgi study, statistical significance was assessed by two-way analysis of variance (ANOVA) followed by Bonferroni posttest to evaluate the effect of genotype in number of prolongations and distance from neuron soma. $p$ values $<0.05$ were considered significant. Reported values represent the mean $\pm S D$ of experiments performed for each marker and each hippocampal area.

In order to simplify graphic presentation, values of WB were expressed as percentages of the $\mathrm{CB}_{1} \mathrm{R}^{+/+}$group (value $=1$ for $\mathrm{WB}$ ).

\section{3 | RESULTS}

\subsection{Neurofilament expression analysis}

Neurofilaments are the most important components of the axonal cytoskeleton and their elastic properties help maintain the markedly asymmetric shape of neurons. As neurofilament dynamic remodeling is essential for axonal growth and maintenance, the study of neurofilament expression reveals whether alterations occur in neuronal functioning (Evrard \& Brusco, 2011; Yuan, Rao, \& Nixon, 2012).

The expression of NF160 and NF200 was analyzed in the stratum radiatum of the hippocampal areas CA1, CA2, CA3, and in the molecular layer of the DG (Figures $1 a, b$ and $2 a, b)$.

$A$ reduction was observed in the area covered by NF160+ and $\mathrm{NF} 200+$ fibers in the CA1 area in CB1 $\mathrm{R}^{-/-}$as compared to $\mathrm{CB} 1 \mathrm{R}^{+/+}$ $\left(\mathrm{NF} 160=\mathrm{CB} \mathrm{R}^{+/+}: 16.11 \pm 3.54\right.$ vs. $\mathrm{CB}^{-1 R^{-/}:}: 12.09 \pm 1.42$, unpaired $t$ test, $t(8)=2.356, p=0.047, n=5$ and NF200 $=\mathrm{CB} \mathrm{R}^{+/+}$:

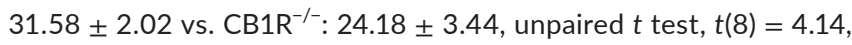

$p=0.029, n=5$ ) (Figures 1c,d,I and 2c,d,I). However, no differences were found between groups in the expression of NF160 and NF200 in the stratum radiatum of CA2 area $\left(\mathrm{NF} 160=\mathrm{CB} \mathrm{R}^{+/+}: 20.32 \pm 5.37\right.$ vs. $\mathrm{CB}_{1 \mathrm{R}^{-/-}}: 16.17 \pm 5.65$, unpaired $t$ test, $t(8)=1.19, p=0.686, n=5$ and NF200 $=\mathrm{CB}_{1 \mathrm{R}^{+/+}: 14.80 \pm 4.75 \text { vs. CB1R }}{ }^{-/-}: 13.16 \pm 2.31$, unpaired $t$ test, $t(8)=0.69 p=0.319, n=5$ ) (Figures $1 \mathrm{e}, \mathrm{f}, \mathrm{m}$ and $2 \mathrm{e}, \mathrm{f}, \mathrm{m}$ ).

A reduction in the area covered by $\mathrm{NF} 160+$ fibers in $\mathrm{CB}_{1} \mathrm{R}^{-/-}$was detected in the CA3 area in the stratum radiatum $\left(\mathrm{NF} 160=\mathrm{CB} 1 \mathrm{R}^{+/+}\right.$:

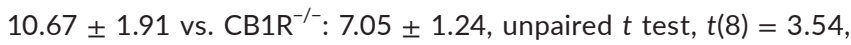
$p=0.045, n=5$ ) (Figure $1 \mathrm{~g}, \mathrm{~h}, \mathrm{n}$ ), with no changes for NF200 $\left(\mathrm{NF} 200=\mathrm{CB} \mathrm{R}^{+/+}: 16.32 \pm 6.53\right.$ vs. $\mathrm{CB} 1 \mathrm{R}^{-/-}: 11.11 \pm 2.48$, unpaired $t$ test, $t(8)=1.66, p=0.096, n=5$ ) (Figure $2 \mathrm{~g}, \mathrm{~h}, \mathrm{n}$ ).

Finally, no significant changes were observed in the area of $\mathrm{NF} 160+$ and NF200+ fibers in the molecular layer of the DG $\left(\mathrm{NF} 160=\mathrm{CB}^{+R^{+/+}}: 14.54 \pm 3.49\right.$ vs. CB1R ${ }^{-/-}: 11.93 \pm 4.89$, unpaired $t$ test, $t(8)=0.96, p=0.473, n=5$ and NF200 $=C_{B} 1 R^{+/+}: 20.97 \pm 3.67$ vs. $C B 1 R^{-/-}: 19.77 \pm 3.28$, unpaired $t$ test, $t(8)=0.54, p=0.289$, $n=5$ ) (Figures 1i,j,o and 2i,j,o).

WB analyses in $\mathrm{CB}_{1} \mathrm{R}^{-/-}$showed a reduction in the expression of NF160 in whole hippocampus with respect to $\mathrm{CB} 1 \mathrm{R}^{+/+}$ $\left(\mathrm{NF} 160=\mathrm{CB} \mathrm{R}^{+/+}: 1.00 \pm 0.28\right.$ vs. CB1R ${ }^{-/-}: 0.46 \pm 0.34$, unpaired $t$ test, $t(8)=2.69, p=0.027, n=5$ ) (Figure $1 \mathrm{k}$ ), which may correspond to the changes observed in each of the hippocampal areas studied. No differences were observed in total NF200 expression in the hippocampus (NF200 $=\mathrm{CB}_{1} \mathrm{R}^{+/+}: 1.00 \pm 0.24$ vs. $\mathrm{CB}_{1 R^{-/-}}: 0.92 \pm 0.23$, unpaired $t$ test, $t(8)=0.52, p=0.616, n=5$ ) (Figure $2 \mathrm{k}$ ).

\subsection{MAP2 expression analysis}

MAP2 is a microtubule-associated protein whose expression is restricted to the neuronal cell body and dendrites (Dehmelt \& Halpain, 2005). The MAP2 protein participates in processes such as arborization and dendritic extension, being commonly used as a specific marker of dendrites.

The stratum radiatum of the hippocampal areas CA1 and CA2 revealed a reduction in the area covered by MAP2+ fibers in $\mathrm{CB} 1 \mathrm{R}^{-/-}$ mice as compared to $C B 1 R^{+/+}$mice $\left(C A 1=C B 1 R^{+/+}: 30.85 \pm 6.33\right.$ vs.

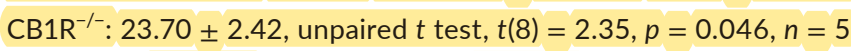

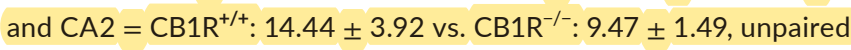
$t$ test, $t(8)=2.64, p=0.029, n=5$ ) (Figure $3 a-m$ ), while the stratum radiatum of CA3 and the molecular layer of the DG rendered no differences between groups $\left(C A 3=\mathrm{CB}^{+/+}: 14.77 \pm 4.31\right.$ vs. $\mathrm{CB} \mathrm{R}^{-/-}: 15.29 \pm 3.37$, unpaired $t$ test, $t(8)=0.21, p=0.83, n=5$ and $\mathrm{GD}=\mathrm{CB} \mathrm{R}^{+/+}: 25.88 \pm 4.32$ vs. $\mathrm{CB}^{-/ R^{-/}}: 23.93 \pm 3.15$, unpaired $t$ test, $t(8)=0.81, p=0.4395, n=5$ ) (Figure 3g,h,n,i,j,o).

WB analyses in whole hippocampus showed a reduction in MAP2 expression in $\mathrm{CB}_{1 \mathrm{R}^{-/-}}$mice compared to $\mathrm{CB}_{1} \mathrm{R}^{+/+}\left(\mathrm{MAP} 2=\mathrm{CB}_{1} \mathrm{R}^{+/+}\right.$: $1.00 \pm 0.33$ vs. $C B 1 R^{-/-}: 0.49 \pm 0.26$, unpaired $t$ test, $t(8)=2.71$, $p=0.026, n=5$ ) (Figure $3 \mathrm{k}$ ), which could correspond with the decrease observed in morphological analyses in the area covered by MAP2+ fibers in the areas CA1 and CA2. 


\section{NF160 / Hoechst}
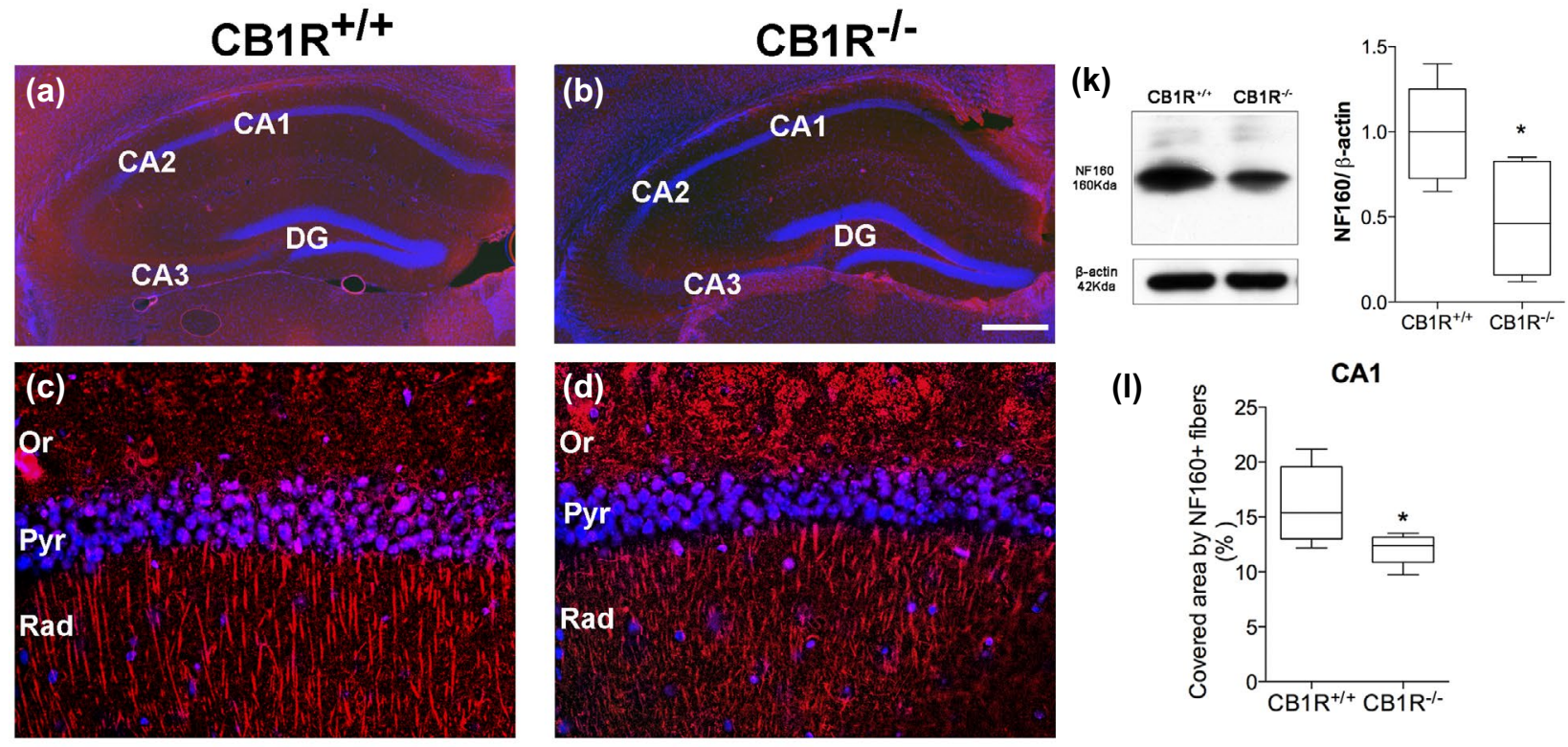

(I)
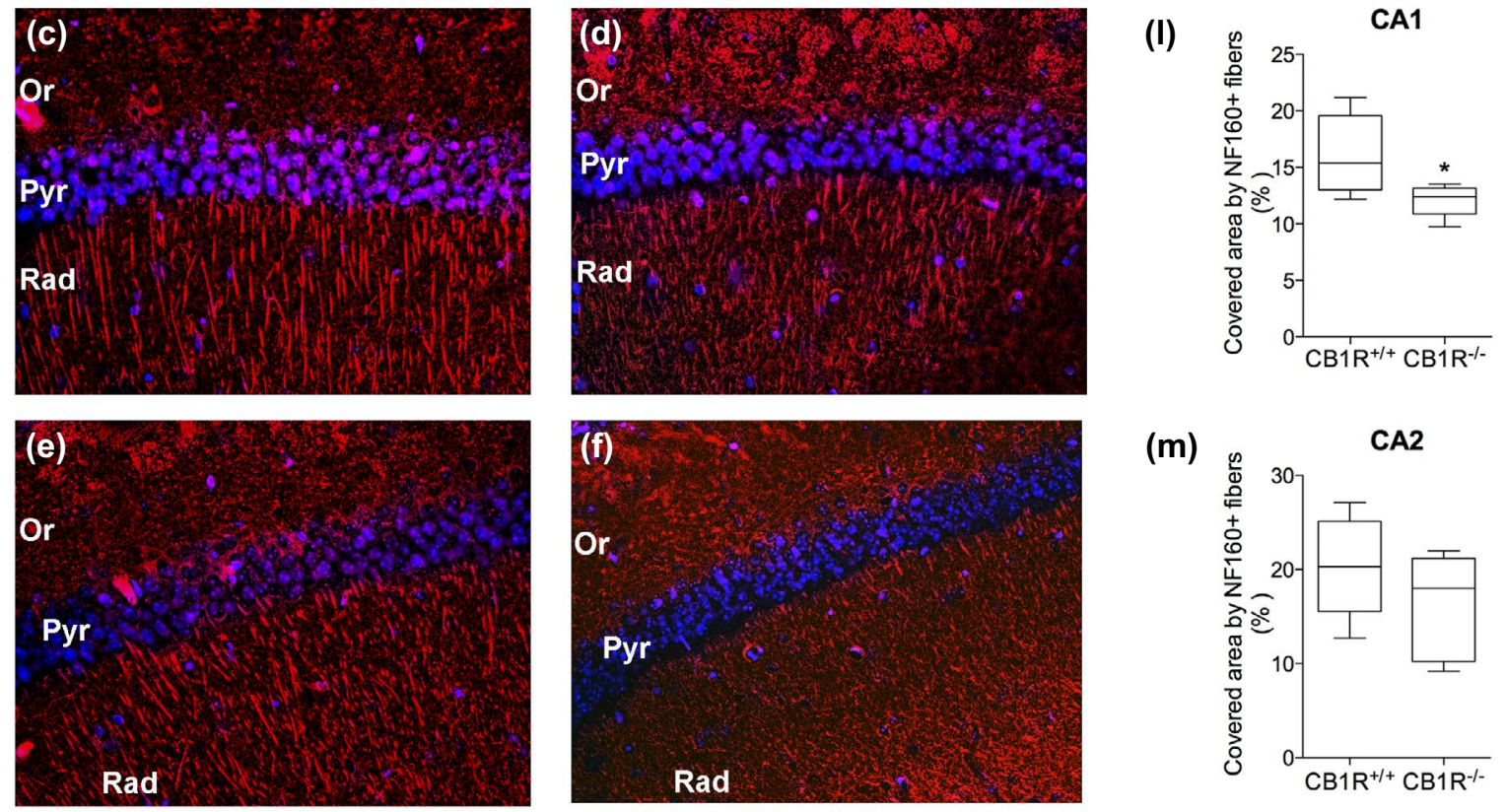

(m)
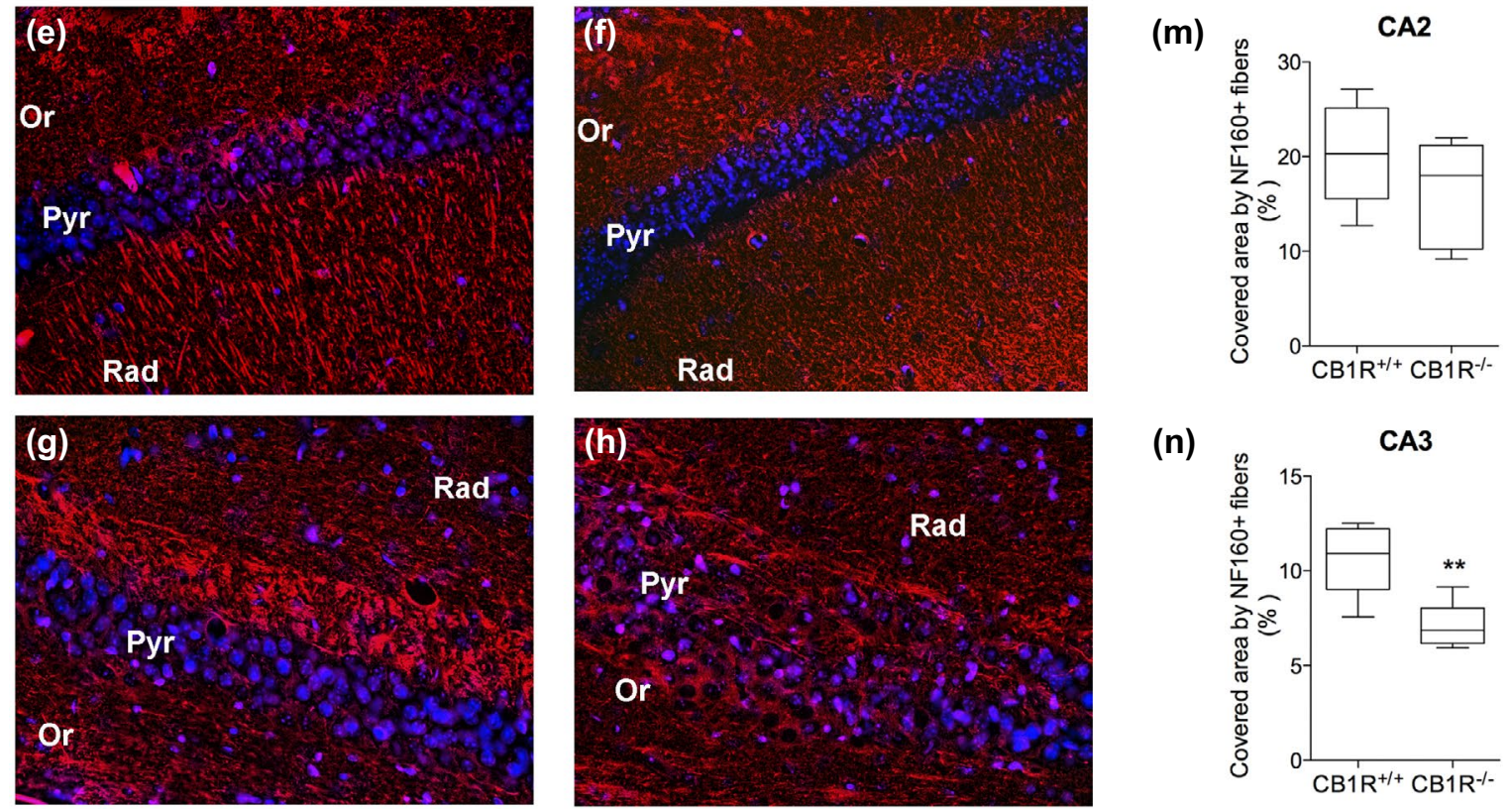

(n)
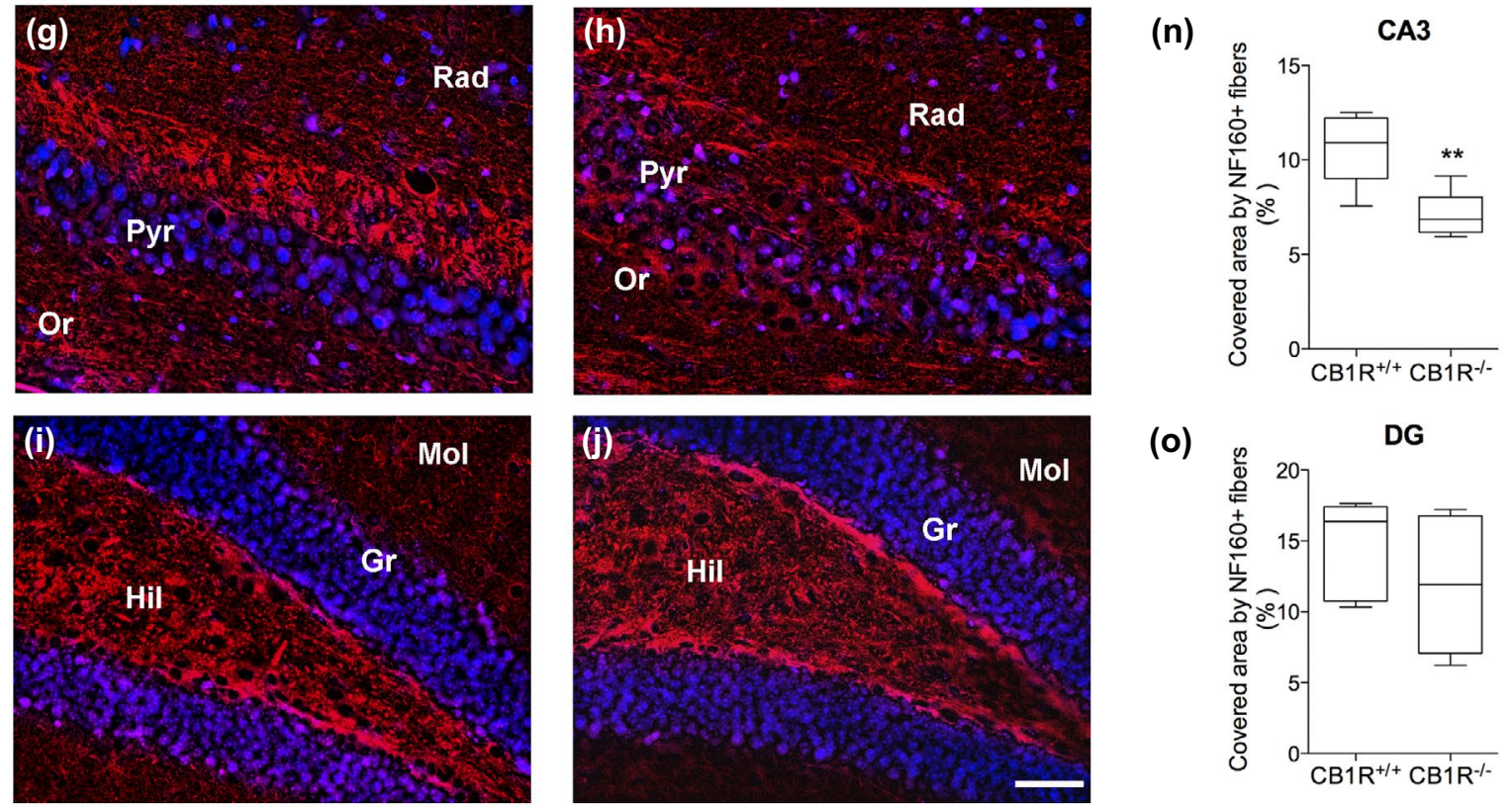

FIGURE 1 NF160 expression in the hippocampus. Immunofluorescence and semiquantification of NF160+ fiber area in CA1 (c, d, and I), CA2 (e, f and m), CA3 (g, h, and n) and the DG (i, j and o) (bars $=30 \mu \mathrm{m})$ from CB1R ${ }^{+/+}$(a) and CB1 ${ }^{-/-}$(b) (bars $\left.=300 \mu \mathrm{m}\right)$. Unpaired t-test, columns represent mean $\pm S D$ ( $n=5$ /group), ${ }^{*} p<0.05$. CA, cornus ammonis; DG, dentate gyrus; Gr, granular layer; Hil, hilus; Mol, molecular layer; Or, stratum oriens; Pyr, pyramidal layer; Rad, stratum radiatum. (k) NF160 protein WB in the hippocampus. Relative optical density of NF160/ $\beta$-actin. Unpaired t-test, bars represent mean $\pm S D$ ( $n=5 /$ group), ${ }^{*} p<0.05$ 

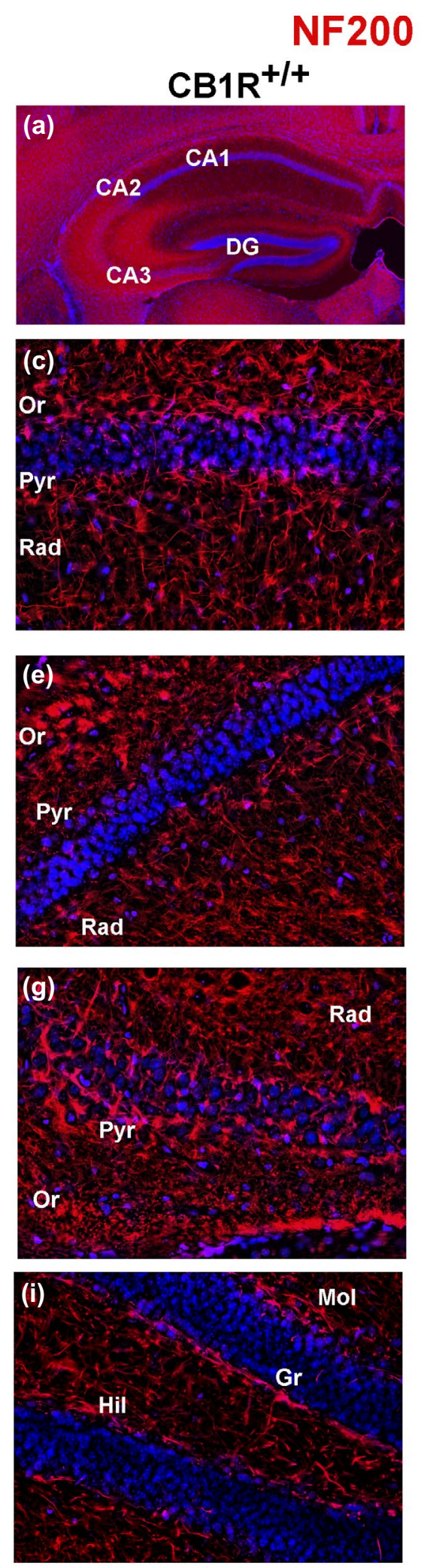

CB1 ${ }^{-I-}$
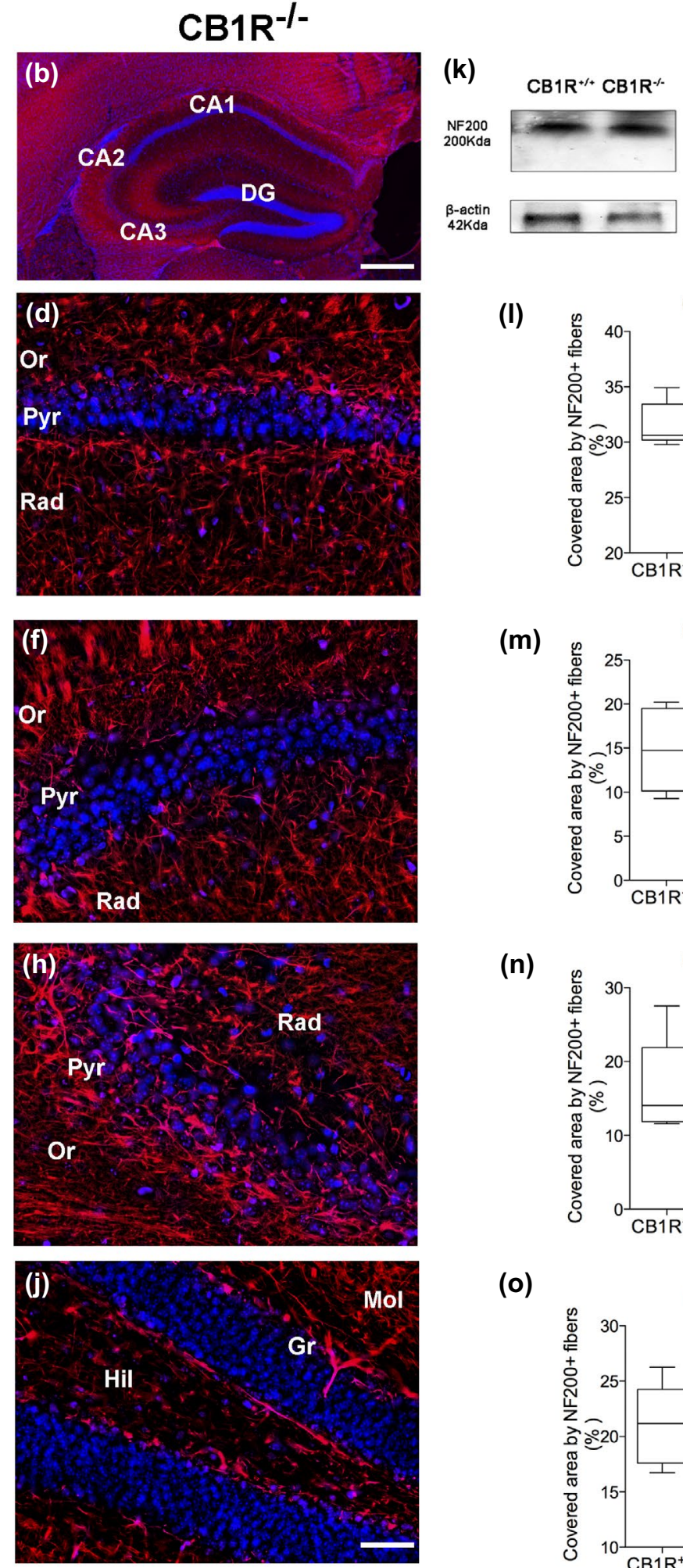

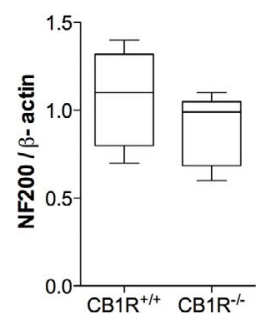

(I)

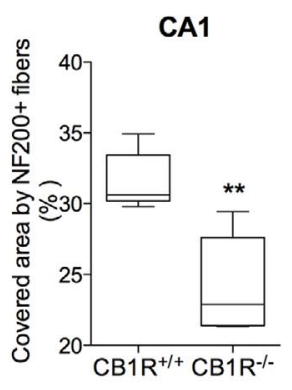

(m)

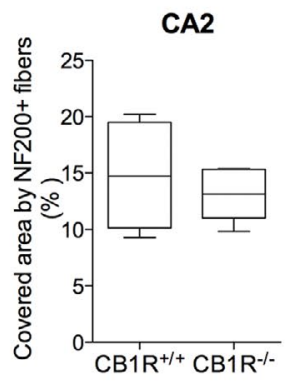

(n)

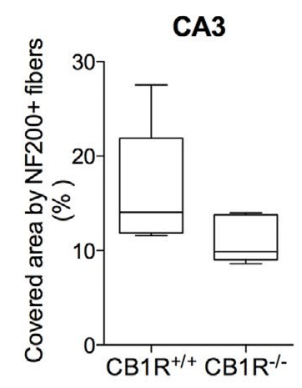

(o)

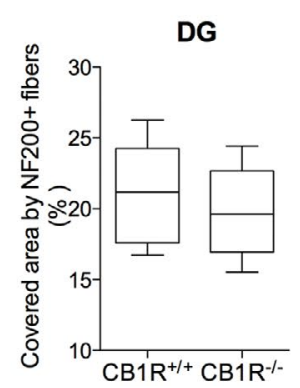

FIGURE 2 NF200 expression in the hippocampus. Immunofluorescence and semiquantification of NF200+ fiber area in CA1 (c, d, and I), CA2 (e, f, and m), CA3 (g, h, and n), and the DG (i, j, and). (bars $=30 \mu \mathrm{m})$ from CB1 ${ }^{+/+}$(a) and CB1 ${ }^{-/-}$(b) (bars $\left.=300 \mu \mathrm{m}\right)$. Unpaired t-test, columns represent mean $\pm S D$ ( $n=5$ /group), ${ }^{*} p<0.05$. CA, cornus ammonis; DG, dentate gyrus; Gr, granular layer; Hil, hilus; Mol, molecular layer; Or, stratum oriens; Pyr, pyramidal layer; Rad, stratum radiatum. (k) NF200 protein WB in the hippocampus. Relative optical density of NF200/ $\beta$-actin. Unpaired $t$-test bars represent mean $\pm S D$ ( $n=5 /$ group), ${ }^{*} p<0.05$ 

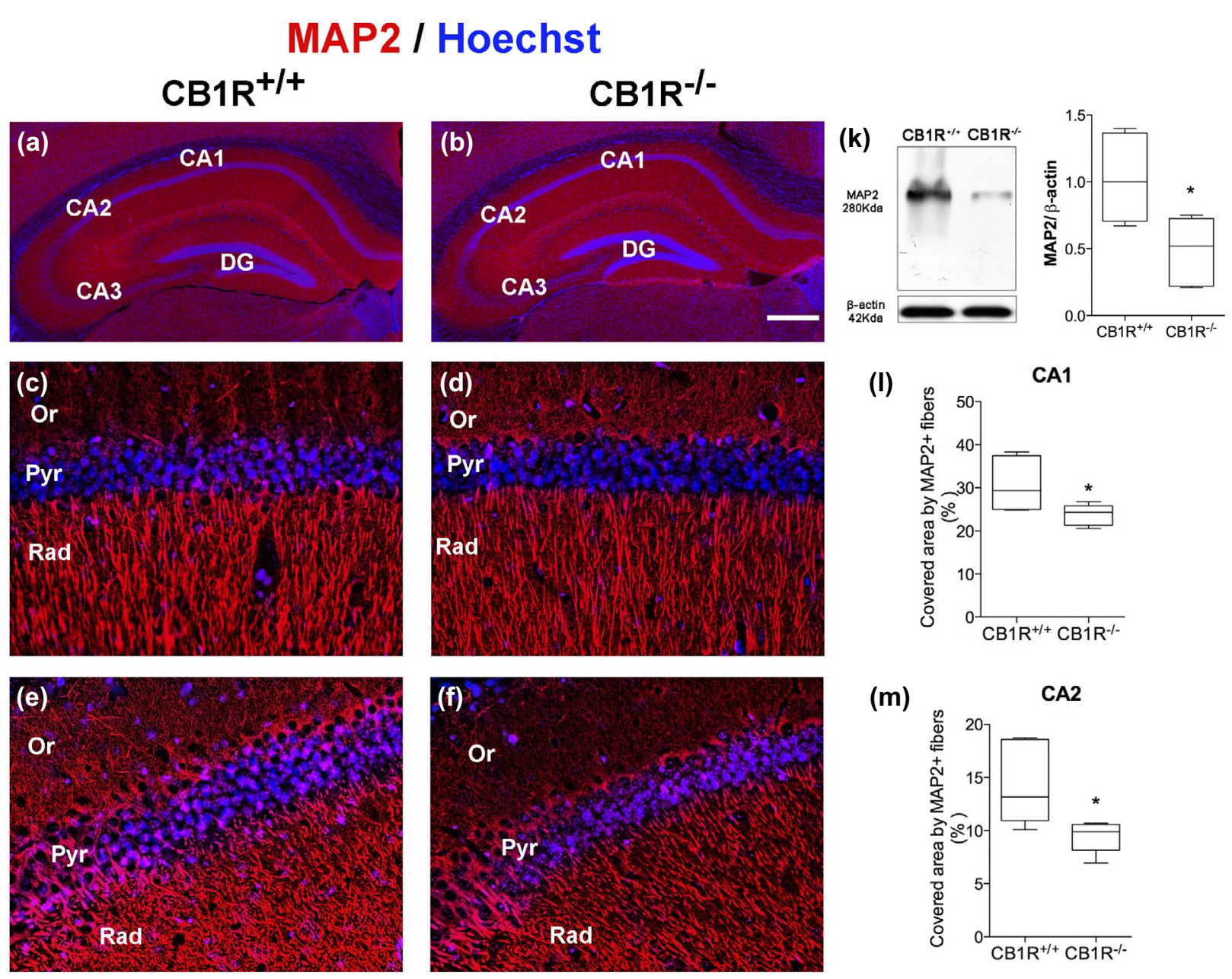

(I)
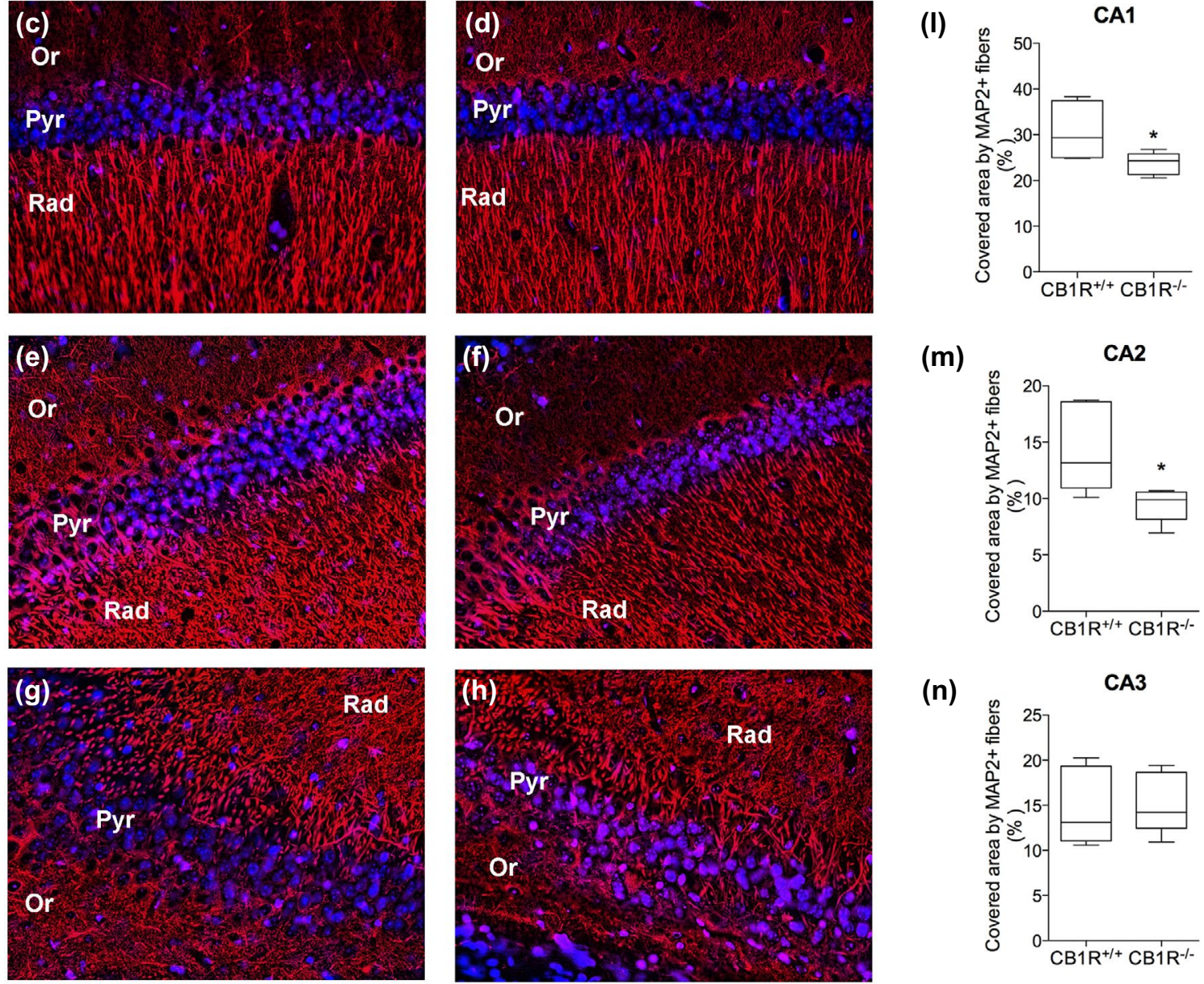

(m)
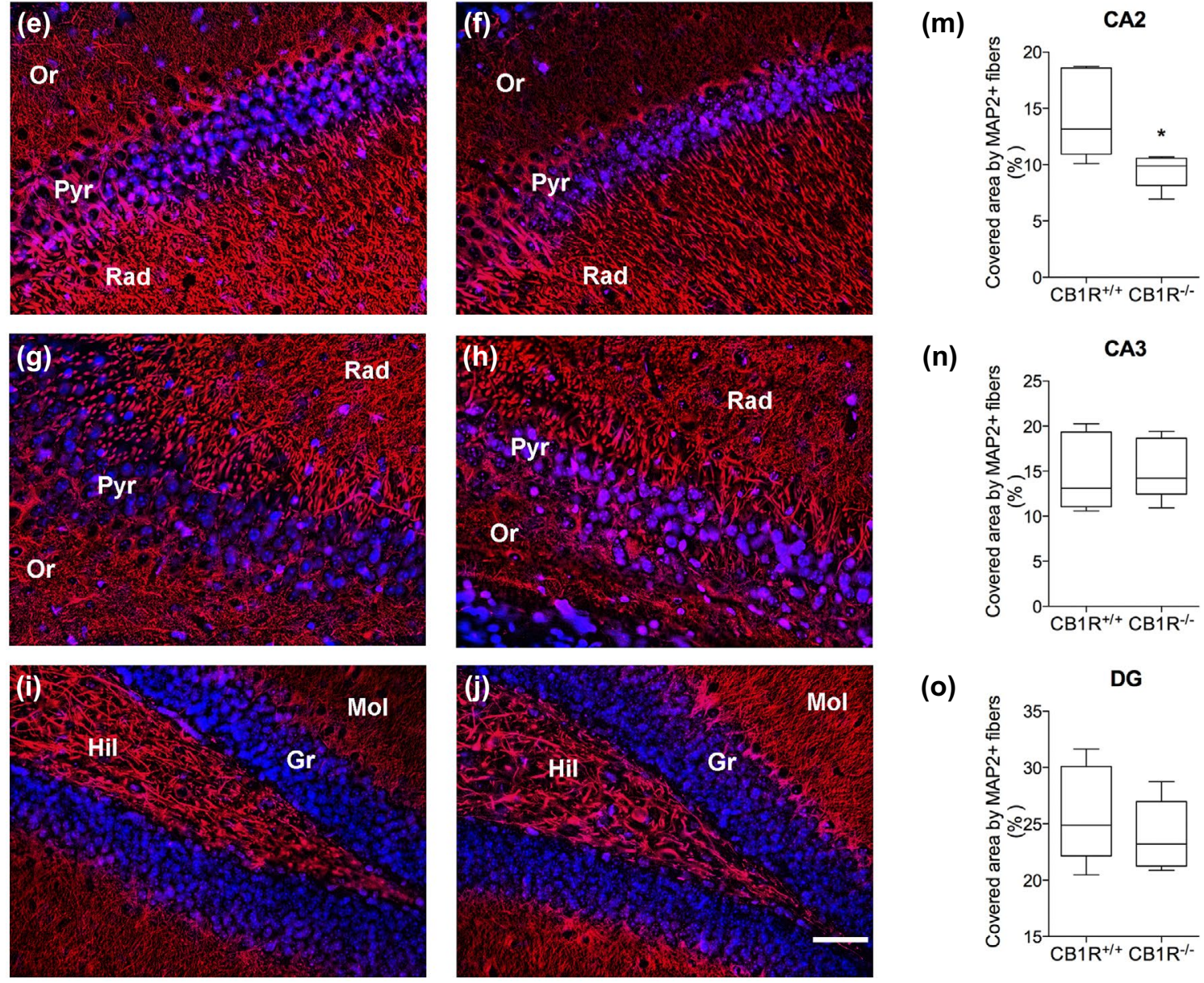

(n)

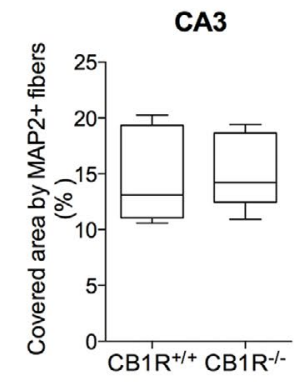

(o)

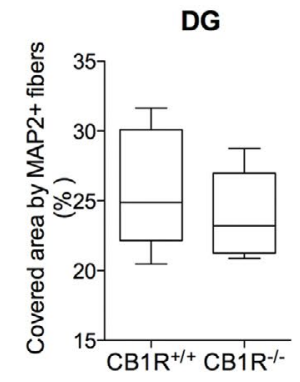

FIGURE 3 MAP2 expression in the hippocampus. Immunofluorescence and semiquantification of MAP2+ fiber area in CA1 (c, d, and I), CA2 (e, f, and m), CA3 (g, h, and n), and the DG (i, j, and o) (bars $=30 \mu \mathrm{m})$ from CB1 $\mathrm{R}^{+/+}$(a) and CB1 $\mathrm{R}^{-/-}$(b) (bars $\left.=300 \mu \mathrm{m}\right)$. Unpaired $t$-test, columns represent mean $\pm S D$ ( $n=5$ /group), ${ }^{*} p<0.05,{ }^{* *} p<0.01$. CA, cornus ammonis; DG, dentate gyrus; Gr, granular layer; Hil, hilus; Mol, molecular layer; Or, stratum oriens; Pyr, pyramidal layer; Rad, stratum radiatum. (k) MAP2 protein WB in the hippocampus. Relative optical density MAP2/ $\beta$-actin. Unpaired $t$-test, bars represent mean $\pm S D(n=5 /$ group $),{ }^{*} p<0.05$ 


\section{3 | Neuronal morphological analysis}

Studies on dendritic intersections and spine density in CA1 hippocampal area, using Golgi technique, showed a significant effect of genotype in the number of dendrites (A two-way ANOVA test number of dendrites $\times$ genotype; apical dendrites $=F(1,16)$ :
33.38, $n=3, p=0.01$; basal dendrites $=F(1,16): 7.04, n=3$, $p<0.01$ ) (Figure 4a,b,e,f) these data are correlated with the reduction in dendritic branching in $\mathrm{CB}_{1} \mathrm{R}^{-/-}\left(\mathrm{CB}_{1} \mathrm{R}^{+/+}: 4,24 \pm 0.327 \mathrm{vs}\right.$. $\mathrm{CB} \mathrm{R}^{-/-}: 3.51 \pm 0.48$, unpaired $t$ test, $t(4)=3.23, p=0.003, n=3$ ) (Figure 4b,d). However, CB1R deficiency induce a reduction in dendritic diameter $\left(\mathrm{CB} 1 \mathrm{R}^{+/+}: 2.05 \pm 0.37\right.$ vs. $\mathrm{CB} 1 \mathrm{R}^{-/-}: 1.43 \pm 0.06$, (a)

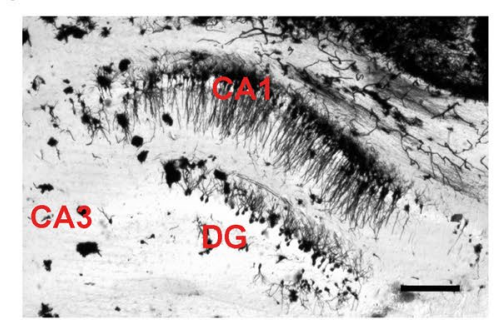

(d)

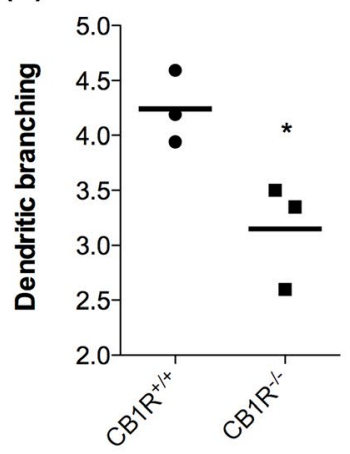

(b) $\quad C B 1 R^{+/+}$

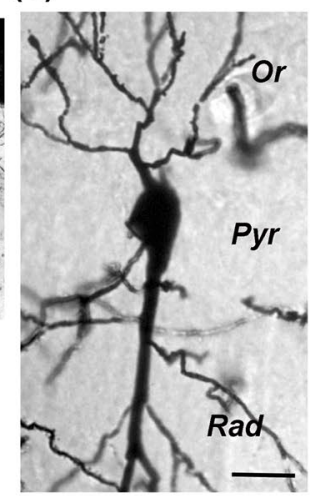

$C B 1 R^{-1-}$

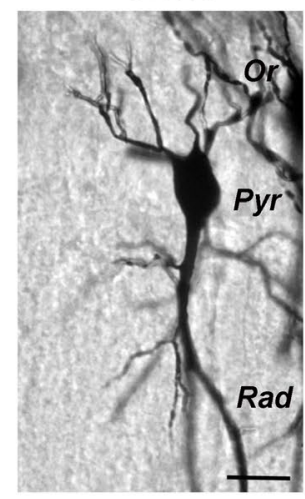

(c)

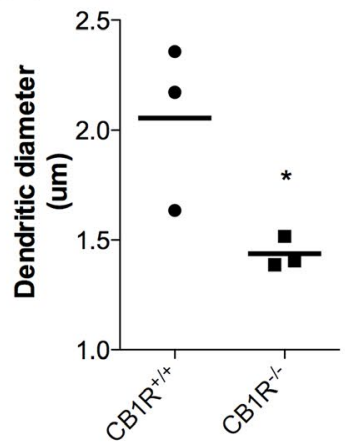

(e)

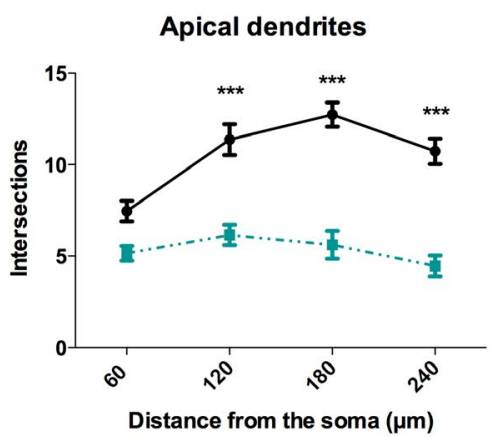

(f)

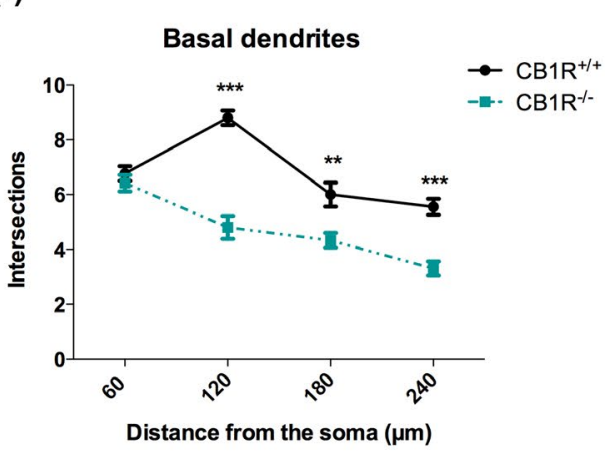

(g)

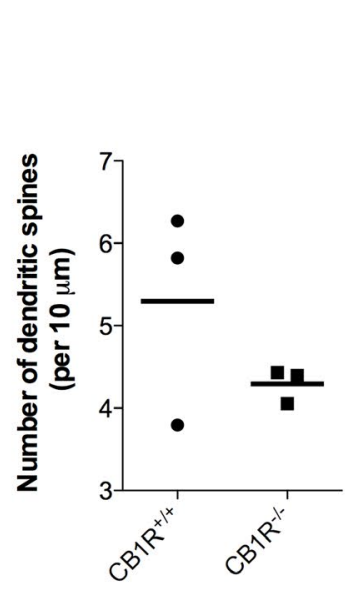

(h)

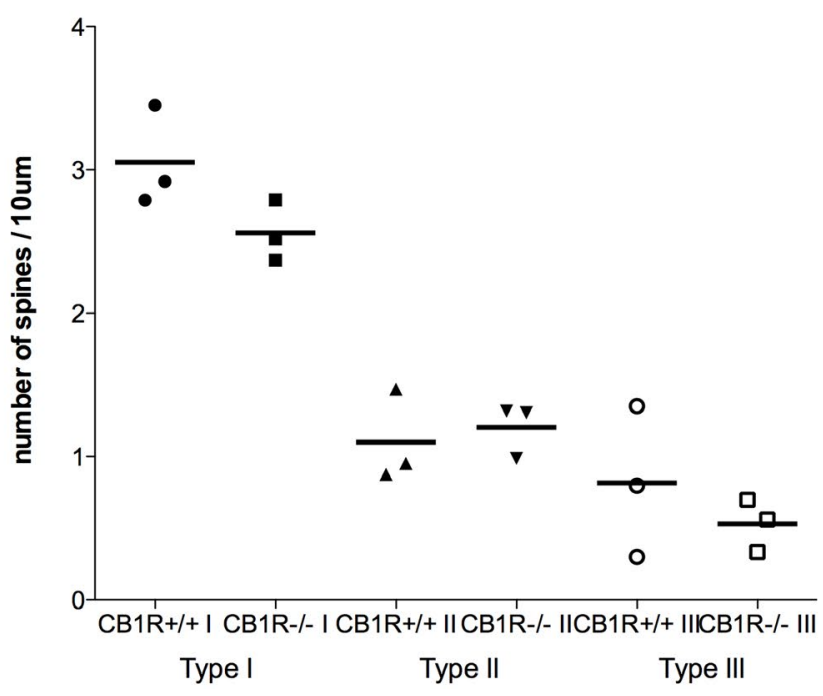

(i)

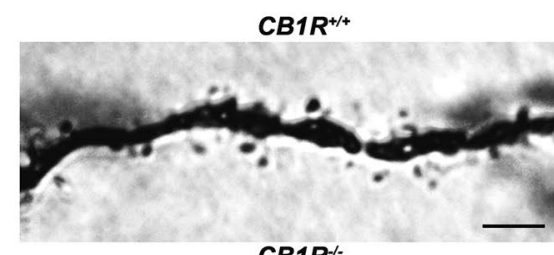

$\mathrm{CB1R}^{-/-}$

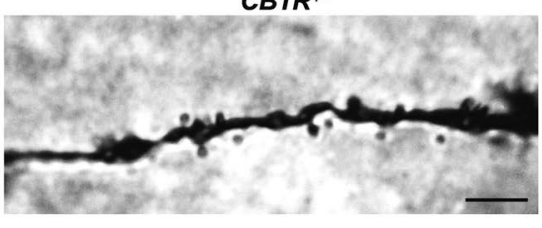

FIGURE 4 Neuronal arborization and dendritic spines in CA1 pyramidal neurons. Golgi staining representative images (a, b, and I; bars $=200,30$, and $5 \mu \mathrm{m}$, respectively), dendritic diameter (c), dendritic branching (d). Unpaired $t$-test, columns represent mean $\pm S D(n=3 /$ group), ${ }^{*} p<0.05$. Number of apical and basal dendrites of pyramidal neuron (e and f) Two-way ANOVA and Bonferroni posttest, columns represent mean $\pm S D$ ( $n=3$ /group), ${ }^{* *} p<0.01,{ }^{* * *} p<0.001$. Number of dendritic spines per $100 \mu \mathrm{m}(\mathrm{g})$, types of spines (h). Unpaired $t$-test, columns represent mean $\pm S D$ ( $n=3 /$ group), ${ }^{*} p<0.05$ 

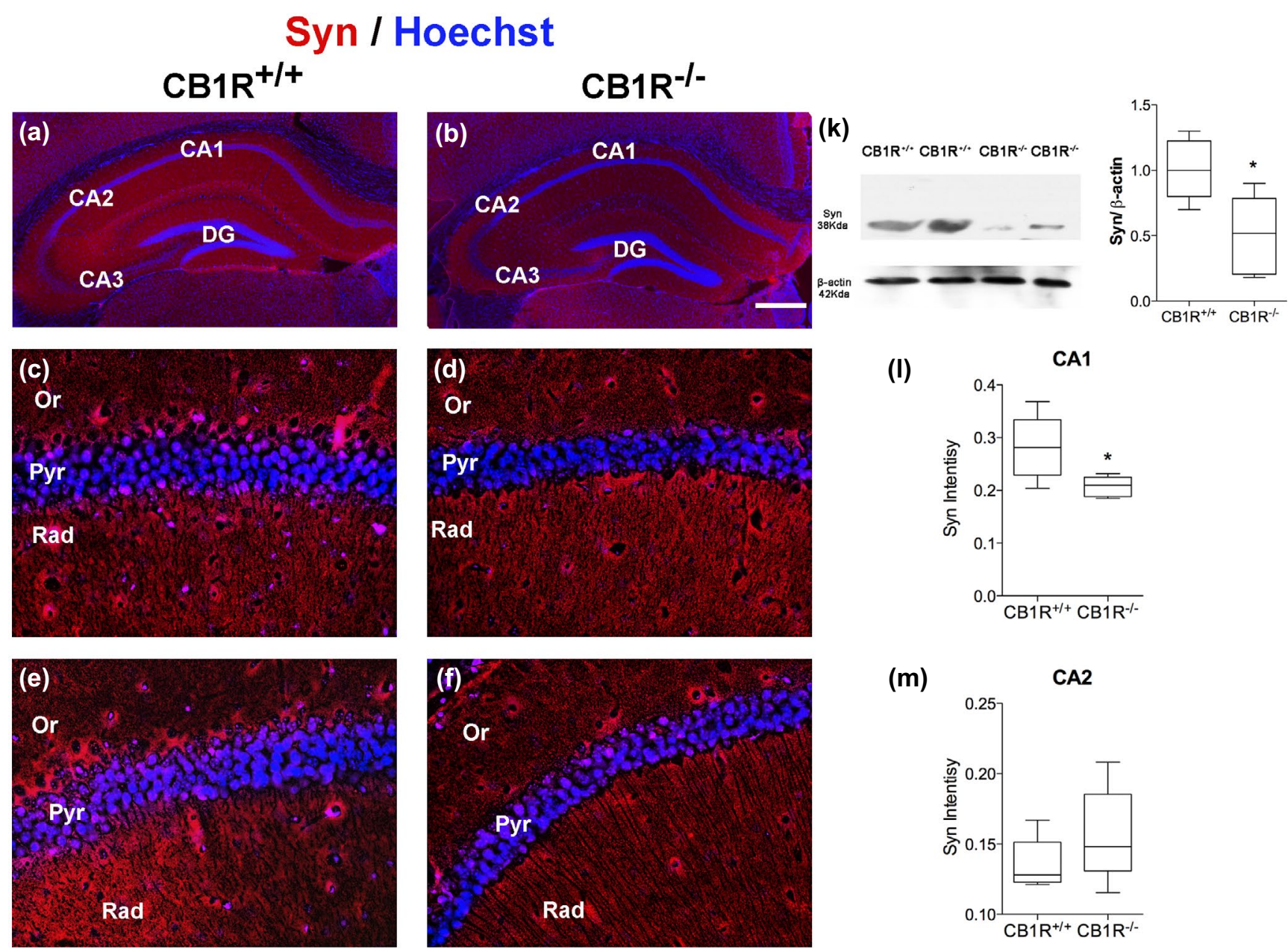

(I)
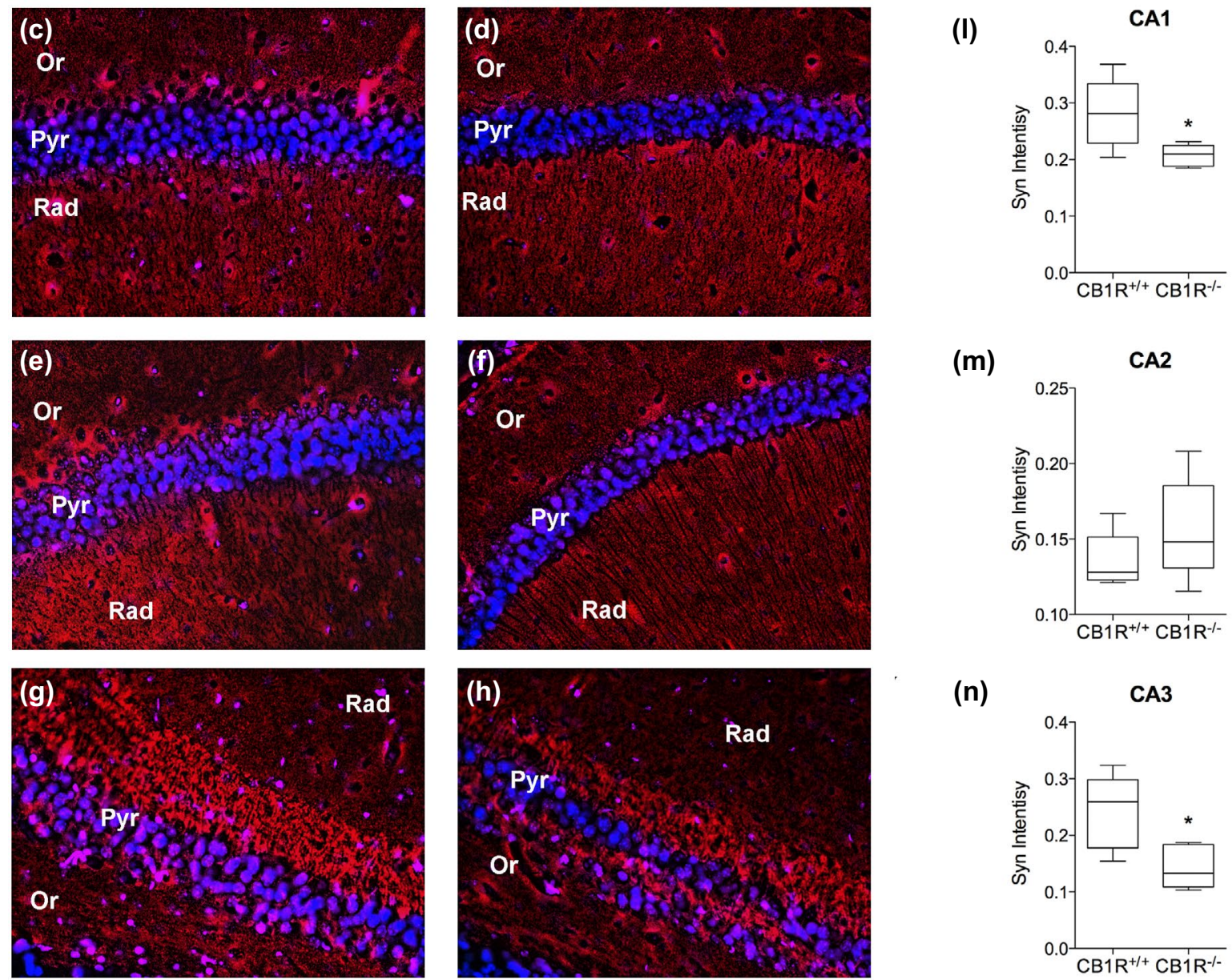

(m)
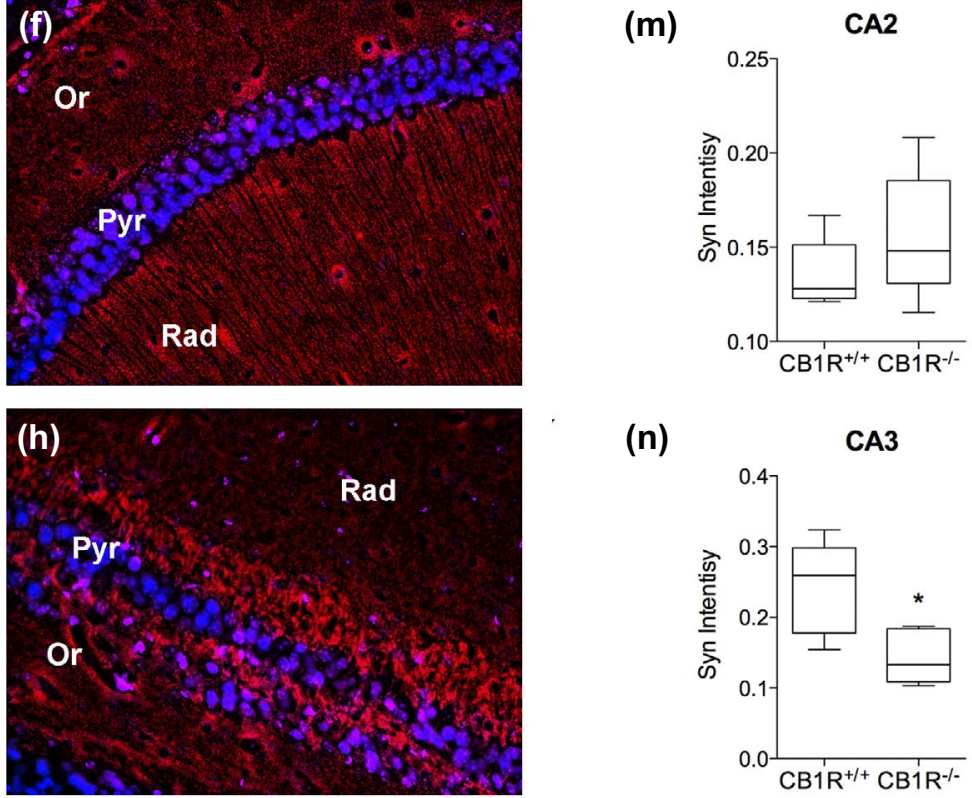

(n)
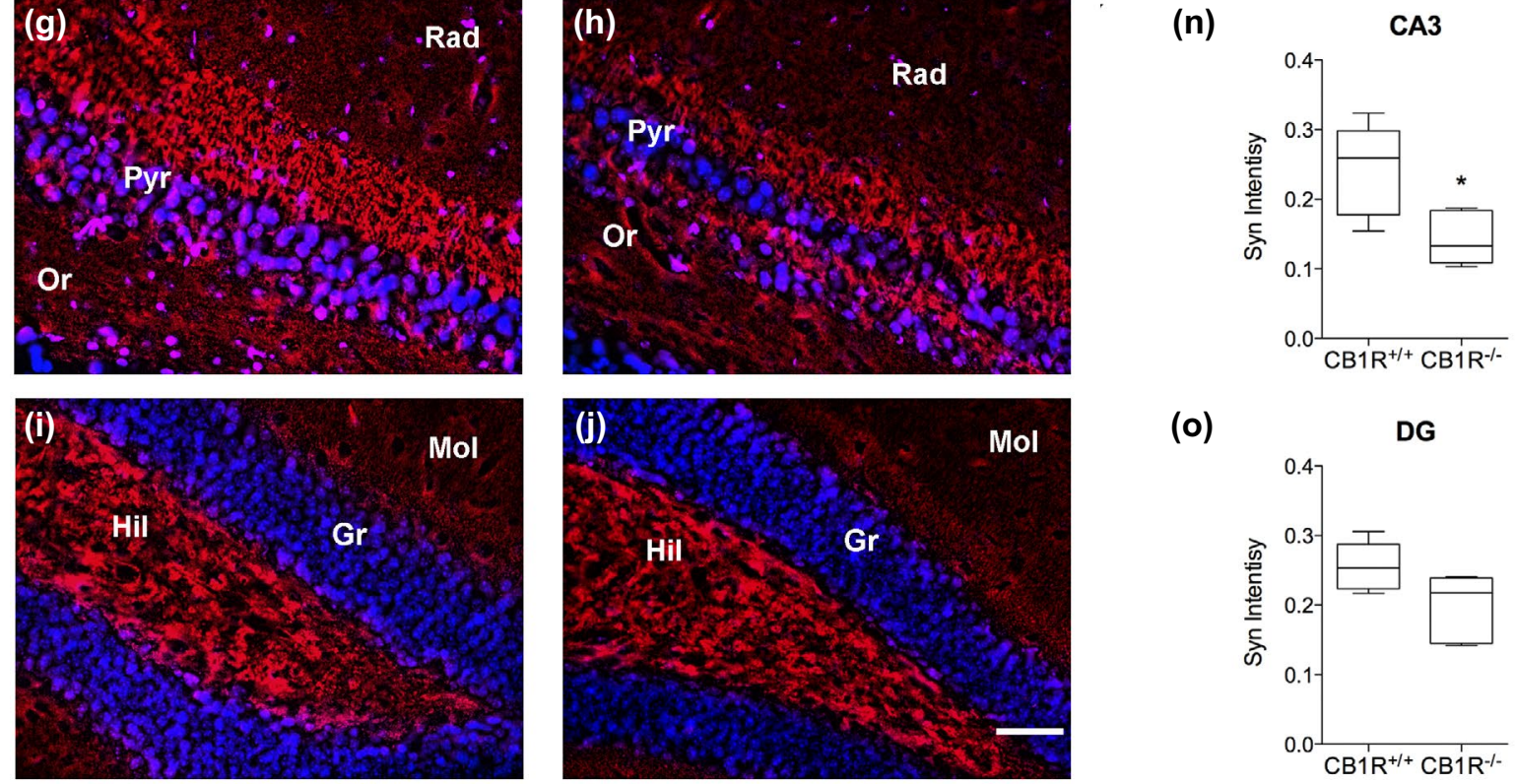

(o)

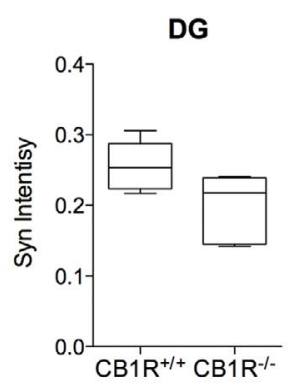

FIGURE 5 Syn expression in the hippocampus. Immunofluorescence and semiquantification of Syn+ intensity in CA1 (c- d and I), CA2 (e$\mathrm{f}$ and $\mathrm{m}$ ), CA3 ( $\mathrm{g}-\mathrm{h}$ and $\mathrm{n}$ ), and the DG ( $\mathrm{i}-\mathrm{j}$ and o) (bars $=30 \mu \mathrm{m})$ from CB1 $\mathrm{R}^{+/+}(\mathrm{a})$ and $\mathrm{CB} 1 \mathrm{R}^{-/-}(\mathrm{b})($ bars $=300 \mu \mathrm{m})$. Unpaired $t$-test, columns represent mean $\pm S D$ ( $n=5$ /group), ${ }^{*} p<0.05$. CA, cornus ammonis; DG, dentate gyrus; Gr, granular layer; Hil, hilus; Mol, molecular layer; Or, stratum oriens; Pyr, pyramidal layer; Rad, stratum radiatum. (k) Syn protein WB in the hippocampus. Relative optical density Syn/ $\beta$-actin. Unpaired t-test, bars represent mean $\pm S D$ ( $n=5 /$ group), ${ }^{*} p<0.05$ 
unpaired $t$ test, $t(4)=2.28, p=0.048, n=3$ (Figure 4c,i) but did not alter the number of dendritic spines $\left(C B 1 R^{+/+}: 5.29 \pm 1.31\right.$ vs. $\mathrm{CB} \mathrm{R}^{-/-}: 4.29 \pm 0.20, t(4)=1.29, p=0.26, n=3$ ) (Figure $4 \mathrm{~g}, \mathrm{i}$ ) also no difference in spine type were observed (Type I: CB1R ${ }^{+/+} 3.05: \pm 0.21$ vs. $\mathrm{CB} 1 \mathrm{R}^{-/-} 2.56 \pm 0.21$, unpaired $t$ test, $t(4)=2.08, p=0.10, n=3$; Type II: CB1R ${ }^{+/+}: 1.1 \pm 0.32$ vs. $\mathrm{CB}_{1 \mathrm{R}^{-/-}} 1.2: \pm 0.18$, unpaired $t$ test, $t(4)=0.48, p=0.65, n=3$; Type III: CB1 $R^{+/+}: 0.81 \pm 0.52$ vs. CB1 ${ }^{-/-}$: $0.53 \pm 0.18$, unpaired $t$ test, $t(4)=0.88, p=0.42, n=3$ ) (Figure $4 h, i)$.

\subsection{Synaptophysin expression analysis}

Synaptophysin is a protein involved in vesicular formation and recycling, which is widely used as a marker for synaptic vesicles.

A reduction in Syn intensity was observed in the stratum radiatum of CA1 and CA3 areas of the hippocampus in CB1R ${ }^{-/-}$(Figure 5a,b; $\mathrm{CA} 1=\mathrm{CB} \mathrm{R}^{+/+}: 0.28 \pm 0.06$ vs. $\mathrm{CB} 1 \mathrm{R}^{-/-}: 0.20 \pm 0.01$, unpaired $t$ test, $t(8)=2.62, p=0.036, n=5$ and $C A 3=C B 1 R^{+/+}: 0.24 \pm 0.06$, vs.

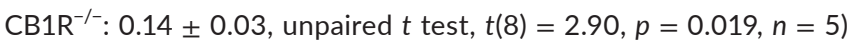
(Figure $5 c, d, I, g, h, n$ ), while no differences were detected in the stratum radiatum of CA2 area or DG $\left(C A 2=\mathrm{CB}_{1} \mathrm{R}^{+/+}: 0.13 \pm 0.018\right.$ vs. $\mathrm{CB} \mathrm{R}^{-/-}: 0.15 \pm 0.03$, unpaired $t$ test, $t(8)=1.21, p=0.258, n=5$ and

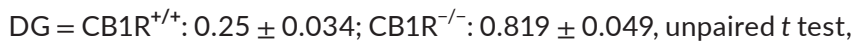
$t(8)=2.17, p=0.061, n=5$ ) (Figure $5 e, f, m, i, j, o$ ).

Syn protein content in the whole hippocampus was lower in $\mathrm{CB}^{-1 /-}$ mice than that in $\mathrm{CB}_{1} \mathrm{R}^{+/+}\left(\mathrm{Syn}=\mathrm{CB}_{1} \mathrm{R}^{+/+}: 1.00 \pm 0.22\right.$ vs. $\mathrm{CB} 1 \mathrm{R}^{-/-}$: $0.49 \pm 0.29$, unpaired $t$ test, $t(8)=3.13, p=0.014, n=5$ ) (Figure $5 \mathrm{k}$ ).

\section{5 | Synaptic ultrastructural analysis}

As observed in electron microscopy studies, CB1R deficiency did not alter the number of synapses in the stratum radiatum of CA1 area of the hippocampus $\left(\mathrm{CB}_{1} \mathrm{R}^{+/+}: 6.02 \pm 2.20\right.$ vs. $\mathrm{CB} 1 \mathrm{R}^{-/-}: 6.90 \pm 2.09$, unpaired $t$ test, $t(2)=0.40, p=0724, n=2$ ) (Figure $6 a, b)$. Regarding synaptic morphology, no differences were found in the number of synaptic vesicles $\left(\mathrm{CB} 1 \mathrm{R}^{+/+}: 7.68 \pm 2.91 \mathrm{vs} . \mathrm{CB} 1 \mathrm{R}^{-/-}: 13.76 \pm 4.70\right.$, unpaired $t$ test, $t(2)=1.15, p=0.260, n=2)$ or synaptic curvature $\left(\mathrm{CB}_{1} \mathrm{R}^{+/+}: 1.13 \pm 0.09\right.$

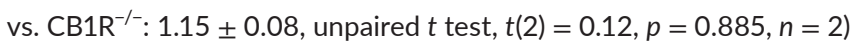
(Figure 7a,b,d). However, CB1R ${ }^{-/-}$evidenced a decrease in the thickness of the postsynaptic density $\left(\mathrm{CB} 1 \mathrm{R}^{+/+}: 6.55 \pm 1.46\right.$ vs. $\mathrm{CB} 1 \mathrm{R}^{-/-}$: $3.19 \pm 1.25$, unpaired $t$ test, $t(2)=3.02, p=0.038, n=2$ ) (Figure $7 a, c)$.

\section{4 | DISCUSSION}

The physiological importance of the endocannabinoid system lies in its role as a neuromodulator of the synaptic activity, participating in central nervous system development, synaptic plasticity, and neurogenesis (Galve-Roperh, Palazuelos, Aguado, \& Guzman, 2009; Oudin, Hobbs, \& Doherty, 2011). Several reports showed that a disruption on endocannabinoid signaling induce alteration in plasticity (Heifets \& Castillo, 2009). Adult CB1R ${ }^{-/-}$mice showed a decreased anandamide (AEA) in hippocampus produced by an increase in AEA membrane transporter (AMT) and its hydrolase, fatty acid amide hydrolase (FAAH) (Maccarrone et al., 2002). Also, repeated
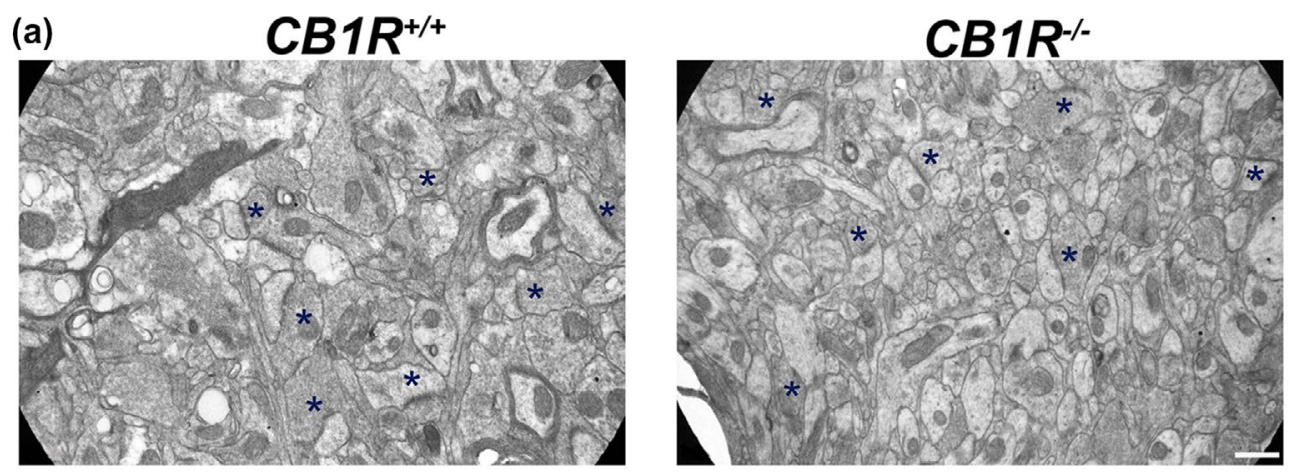

(b)

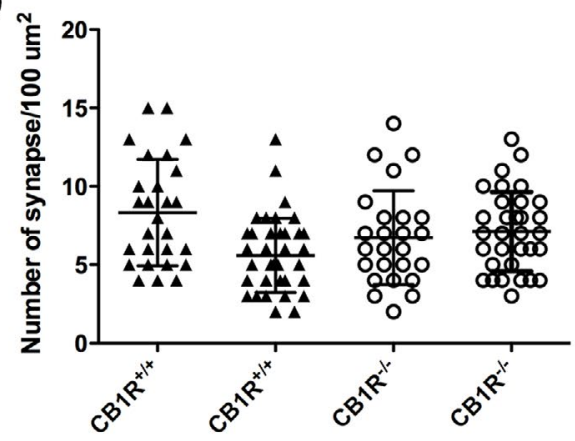

FIGURE 6 Synapses in stratum radiatum of CA1 area. Transmission electron microscopy (a) (bars $=0.5 \mu$ m). Asterisks represent synapses. Number of synapses per $100 \mu \mathrm{m}^{2}$ (b). Unpaired $t$-test, columns represent mean $\pm S D\left(n=2 /\right.$ group), ${ }^{*} p<0.05$ 
(a)

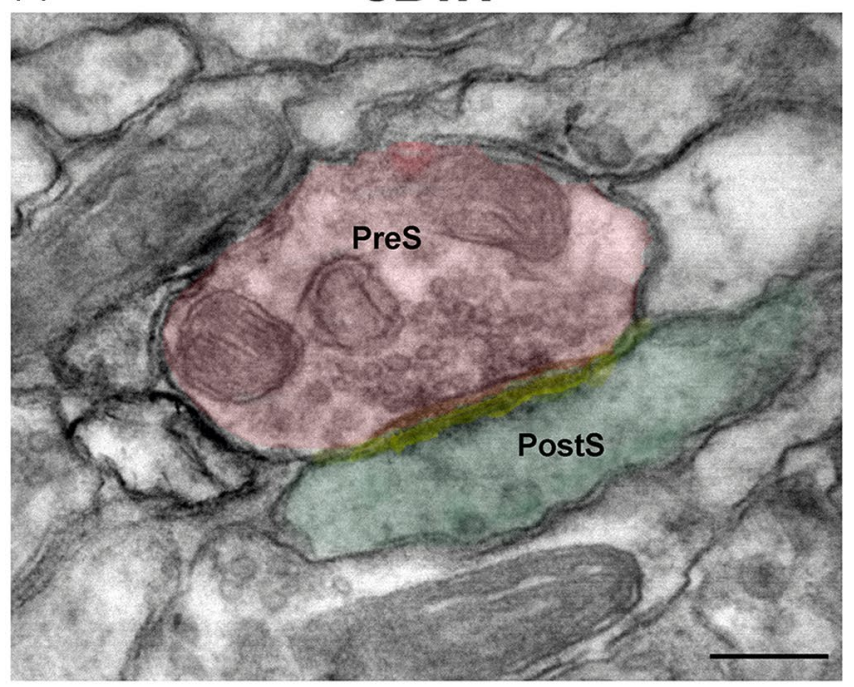

(b)

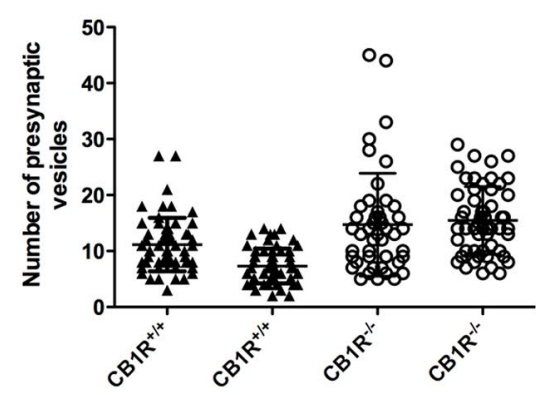

(c)

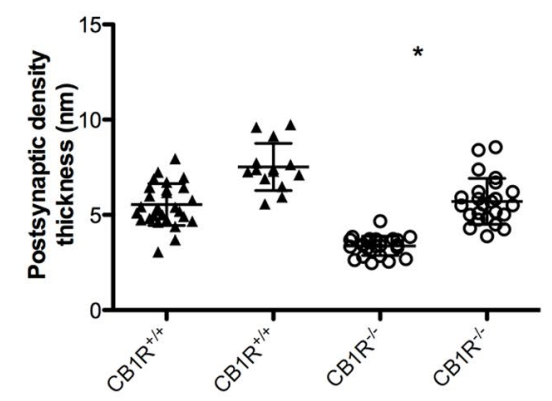

$\mathrm{CB1R}^{-1}$

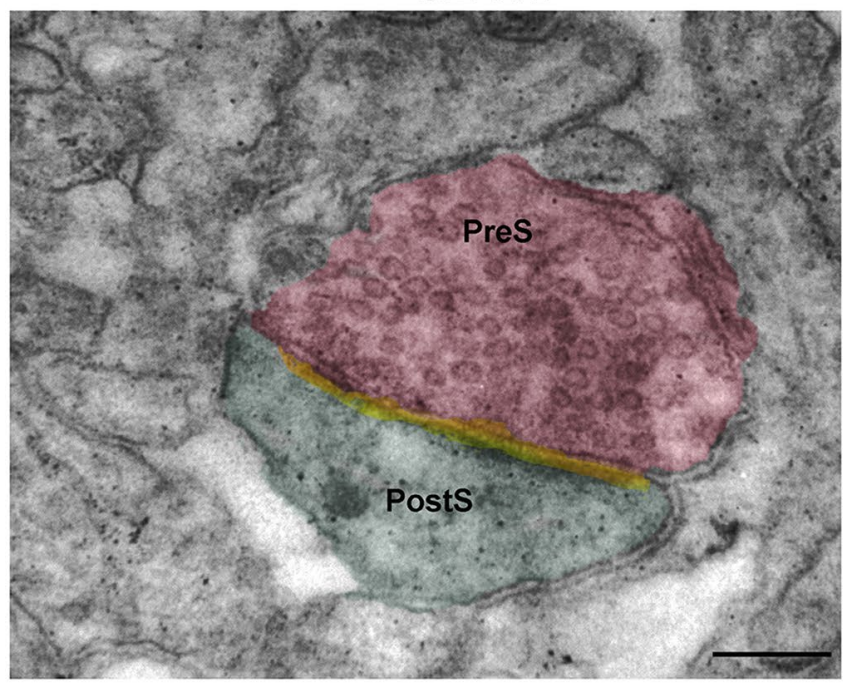

(d)

FIGURE 7 Synaptic ultrastructure in stratum radiatum of CA1 area. Transmission electron microscopy of synapses (a). Number of presynaptic vesicles (b). Postsynaptic density thickness (c). Relation between synaptic length in the synaptic cleft and distance between the synaptic ends (d) (bars $=200 \mathrm{~nm}$ ). Unpaired t-test, columns represent mean $\pm S D\left(n=2 /\right.$ group), ${ }^{*} p<0.05$. PreS, presynaptic neuron; PostS, postsynaptic neuron

FAAH inhibitor treatment reduced neuronal proliferation with decreased expression of CB1R in the hippocampus (Rivera et al., 2015). Moreover, inactivation of MAGL induce increased spine density in pyramidal neuron and improves basal synaptic transmission and long-term synaptic plasticity in the hippocampus (Chen et al., 2012).

All these evidences show that the dysregulation of the endocannabinoid system induces changes in neuronal plasticity. Here we focus on the effect of CB1 deficiency on neuronal and synaptic architecture. Particularly, the changes in neuronal plasticity via CB1R have been associated with its participation in the modulation of the remodeling of the cytoskeleton both in neuronal development and in adult life (Njoo et al., 2015; Tortoriello et al., 2014; Zimmermann et al., 2018). These changes involve alterations in the stability of microtubules and in the dynamics of the actin filaments and are correlated with the determination of the axonal diameter and the growth of neurites.

CB1R is expressed in the pyramidal cell layer of the CA1-CA3 region and highly expressed in the stratum radiatum of these areas and in the molecular layer of the DG. Furthermore, inputs from glutamatergic pyramidal cells of the entorhinal cortex terminate in all areas of the hippocampus and hypothalamic glutamatergic projections terminate mostly in the molecular layer (Steindel et al., 2013). Specifically, CB1R is present in sites where basket cell terminals surround pyramidal and granular cells. Lower CB1R expression is observed in the interconnecting network of inhibitory interneurons innervating the dendritic tree of pyramidal or granular cell bodies in the molecular layer, radiatum, and oriens (Katona et al., 1999).

Steindel and colleagues showed that CB1R deficiency in cortical glutamatergic neurons (Glu-CB1-KO mice) resulted in no apparent change in the CB1R expression pattern in the hippocampal formation but specific deletion of CB1R from GABAergic neurons induced a loss of CB1R protein in the hippocampus, especially in the stratum radiatum of the CA1-CA3 regions, and in the outer two-thirds of the molecular layer of the DG (Steindel et al., 2013).

Taking in account that CA1-CA3 hippocampal areas receive principally forebrain GABAergic inputs, changes observed in this study could due to CB1R deficiency in local hippocampal neurons in addition to $C B 1 R$ deficiency in neuron inputs from other brain areas.

$\mathrm{CB}_{1} \mathrm{R}^{-/-}$mice exhibit behavioral alterations similar to those described in animal models of stress or depression, as endocannabinoid signaling in corticolimbic structures such as the prefrontal cortex, 
amygdala, and hippocampus plays a key role in depression and stress response (Lee, Hill, \& Lee, 2016; Smaga, Bystrowska, Gawliński, Przegaliński, \& Filip, 2014). CB1R deficiency produce alterations in learning and memory process and deficit in long-term plasticity in the hippocampus, the principal area involved in cognitive function (Bannerman et al., 2014; Marsicano \& Lafenetre, 2009). Some of the behavioral changes in $\mathrm{CB}_{1} \mathrm{R}^{-/-}$are associated with changes in the function and morphology of structures of the limbic system and the serotoninergic system, among others.

Low dose of delta-9-tetrahydrocannabinol (THC) improves altered cognitive functions and increased hippocampal spine density and enhances the expression of synaptic proteins of 12-18 months aged mice (Bilkei-Gorzo et al., 2017). Young $\mathrm{CB}^{-/ \mathrm{R}^{-/}}$mice do not show memory or cognitive impairment when compared with $\mathrm{CB}_{1} \mathrm{R}^{+/+}$mice. In contrast, decline in cognitive functions and learning is accelerated in mature and older $\mathrm{CB}_{1} \mathrm{R}^{-/-}$mice. These modifications are also accompanied by neuronal loss in hippocampus (Albayram et al., 2011; Bilkei-Gorzo et al., 2005). Chronic treatment with CB1R cannabinoid agonist during adolescence produces a decrease in arborization and spine density in pyramidal neurons of the prefrontal cortex (Miller et al., 2018; Renard et al., 2016) and in granular neurons of the hippocampus in the adult (Rubino et al., 2009). Controversially, chronic treatment with THC during adulthood increases neuronal arborization in prefrontal cortex (Kolb, Gorny, Limebeer, \& Parker, 2006; Kolb, Li, Robinson, \& Parker, 2018).

In the present work, morphological changes in the hippocampus of $\mathrm{CB}_{1} \mathrm{R}^{-/-}$were evidenced as a decrease in the expression of cytoskeletal proteins, as well as lower dendritic arborization in the stratum radiatum of CA1 area, without changes in length. In addition, in the absence of CB1R, changes in synaptic structure were observed as lower thickness of postsynaptic density and a reduction in Syn levels. However, no changes were detected in the number of dendritic spines, synapses, or synaptic vesicles in neurons in the CA1 area of $\mathrm{CB} 1 \mathrm{R}^{-/-}$mice.

The organization of the neuronal cytoskeleton plays an important role both in neuronal structure and functionality and synaptic plasticity. Neurofilaments are the major components of the neuronal cytoskeleton, and are present in dendrites and particularly abundant in the axon (Yuan et al., 2012). In turn, MAP2 is a protein that maintains the stability of neuronal microtubules and is present in dendrites, where it participates in processes such as dendritic arborization and dendritic extension (Dehmelt \& Halpain, 2005).

The present report shows a decrease in NF160+ and NF200+ fibers in the stratum radiatum of the CA1 area, in NF160+ fibers in stratum radiatum of the $\mathrm{CA} 3$ area, and in MAP2+ fibers in the stratum radiatum of the CA1 and CA2 areas of the hippocampus of CB1 ${ }^{-/-}$. In contrast, no alterations were detected in the expression of neurofilaments or MAP2 in the molecular layer of the DG in the absence of CB1R. Changes in the expression of neurofilaments and MAP2 in the stratum radiatum of the hippocampus evidence the participation of CB1R in the establishment and maintenance of the neuronal cytoskeleton and reinforce the notion of CB1R participation in the dynamics of the neuronal cytoskeleton. Changes in neuronal cytoarchitecture observed in the present study is in agreement with previous studies in different animal models with CB1R agonist, consider that long-term administration of cannabinoid agonists produces a downregulation of receptor (Nogueras-Ortiz \& Yudowski, 2016; Sim-Selley, 2003; Sim-Selley et al., 2006; Wu et al., 2008). Treatment with $\mathrm{THC}$ reduces the expression of microtubules and microfilament in cell cultures (Tahir, Trogadis, Stevens, \& Zimmerman, 1992; Wilson Jr., Tahir, Mechoulam, Zimmerman, \& Zimmerman, 1996). Tagliaferro et al. (2006) have reported an increase in NF160, NF200, and MAP2 in the CA1 area induced by chronic treatment with WIN 55,212-2, a cannabinoid agonist. A proteomic study in hippocampi of animal exposed to THC shows altered expression of cytoskeleton and structural proteins (Quinn et al., 2008) and this may reflect modification in the microtubule cytoskeleton reported by cannabinoid treatment. In addition, a decrease in NF200 expression has been reported in both normal and pathological conditions in $\mathrm{CB}^{-1 /} \mathrm{R}^{-/}$(Jackson, Pryce, Diemel, Cuzner, \& Baker, 2005). Taking into account previous studies and the results reported here, CB1R could play a fundamental role in the organization of the cytoskeleton, participating in the formation and stability of synaptic connections.

Dendrites are the most numerous postsynaptic elements of the central nervous system, and their length and branching are associated with neuronal plasticity. The neuronal branching was reduced in apical and basal dendrites in pyramidal neurons of CA1 area in $\mathrm{CB}_{1} \mathrm{R}^{-/-}$. Additionally, $\mathrm{CA} 1$ pyramidal neurons present lower dendritic branching and dendrite diameter in absence of CB1R. Moreover, a decrease was observed in the expression of MAP2 in the stratum radiatum of CA1 and CA2 areas, which showed that CB1R is participating in the stabilization of the dendritic cytoskeleton and participates in the process of arborization. Similar changes in morphology including a decrease in dendritic arborization and number of spines have been reported in a recent study where CB1R was specifically deleted in GABAergic neurons in the CA1 area of the hippocampus (Monory et al., 2015). The absence of CB1R specifically in new hippocampal neurons during adult life produces alterations in neuritogenesis as a reduction in dendritic length and a lower density of dendritic spines (Zimmermann et al., 2018).

However, in the present study no differences were observed in the number and type of dendritic spines, which depends mainly of actin microfilaments (Gordon-Weeks \& Fournier, 2014). In addition, the decrease in the number of primary prolongations and the alterations in dendrite structure and the possible changes in the stability of microtubules determined by a decrease in MAP2 protein indicate morphological alterations due to CB1R deficiency.

Reduction of neuronal and dendritic arborization with lower dendritic diameter could alter dendrites, spine, and synapse stabilization in the absence of CB1R. The morphology of dendritic spine is related with different in synaptic function (Arellano, BenavidesPiccione, DeFelipe, \& Yuste, 2007), changes in proportion of spine type correlate with different synaptic efficiency and also represent forms of synaptic plasticity in the hippocampus (Bourne \& Harris, 2008; Popov et al., 2004). In the present work, we report a reduction 
in dendritic branching and lower dendrite diameter but changes in proportion or number of dendritic spine were not observed, this is differential effect in structure of dendrite by deletion of CB1R and could be related with different participation in the process of dendritogenesis and spinogenesis.

The alterations observed in the neuronal cytoskeleton and the morphology of pyramidal neurons in the $\mathrm{CA} 1$ area of $\mathrm{CB} 1 \mathrm{R}^{-/-}$could produce deficiencies in synaptic communication. In the present study, the analysis of neuronal connections in the stratum radiatum of CA1 area revealed no differences in the number of synapses between $\mathrm{CB}_{1 \mathrm{R}^{+/+}}$and $\mathrm{CB} 1 \mathrm{R}^{-/-}$. However, CB1R deficiency was seen to produce structural changes such as lower Syn expression and lower thickness of postsynaptic density.

The implication of CB1R in the synaptic structure has also been reported in the work of Tagliaferro et al. (2006), which shows an increase in the number of vesicles as a result of treatment with a cannabinoid agonist and hence supports the hypothesis of a direct effect of cannabinoids on synaptic stability (Karanian, Brown, Makriyannis, Kosten, \& Bahr, 2005). More recently, Buceta et al. show that cerebellar lobules of $\mathrm{CB}_{1} \mathrm{R}^{-/-}$mice contain greater length of synapsis and lower vesicle density, representing ultrastructural adaptations in the absence of CB1R (Buceta et al., 2019). However, in the present work, the number of synaptic vesicles detected by electron microscopy did not show differences between $C B 1 R^{-/-}$ and $\mathrm{CB}_{1} \mathrm{R}^{+/+}$.

Since, Syn is not essential for neurotransmission but modulate the efficiency of the synaptic vesicle cycle (Gordon \& Cousin, 2016). In Syn-deficient mice, hippocampal neurons exhibited defective synaptic vesicle endocytosis both during and after neuronal activity (Kwon \& Chapman, 2011). Complete loss of Syn impairs learning and memory (Schmitt, Tanimoto, Seeliger, chaeffel, \& Leube, 2009) but does not affect viability (Eshkind \& Leube, 1995). Our data indicate that a decrease in Syn may not imply a lower number of synaptic vesicles, but a decrease in Syn expression in each synaptic vesicle. Stratum radiatum of $\mathrm{CA} 3$ area of $\mathrm{CB}_{1} \mathrm{R}^{-/-}$also showed a reduction in Syn expression as compared to $\mathrm{CB} 1 \mathrm{R}^{+/+}$, which, together with the smaller area covered by NF160 fibers, may respond to the lower density of neurons reported in that area of adult CB1R ${ }^{-/-}$(Albayram et al., 2011; Bilkei-Gorzo et al., 2005). On the other hand, the decrease observed in the thickness of the postsynaptic density in the stratum radiatum of $\mathrm{CA} 1$ area of $\mathrm{CB}_{1} \mathrm{R}^{-/-}$could be related to the changes observed in cytoskeletal components. In other words, alterations in cytoskeletal dynamics may lead to changes in the interaction of actin filaments with postsynaptic density proteins (Gordon-Weeks \& Fournier, 2014; Okabe, 2007). This type of morphological change in the CA1 area of the hippocampus has also been studied in rats under conditions of hypoxia, which also showed a decrease in the thickness of postsynaptic density (Von Lubitz \& Diemer, 1983). Changes in postsynaptic density may reflect alterations in the density of postsynaptic receptors and in proteins associated with receptor-mediated signaling, which lead to defective neuronal communication. Therefore, CB1R deficiency can be thought to cause both presynaptic and postsynaptic changes affecting synaptic transmission. Alterations in neuronal structural and synaptic vesicle protein in CA1-CA3 area (Tables S1 and S2) may be related to changes in synaptic communication of intrahippocampal connectivity observed in $\mathrm{CB}_{1 \mathrm{R}^{-/-}}$(Bohme et al., 2000; Jacob et al., 2012) and deficit memory reported in mice evaluated in the present work (Mikics et al., 2006).

In sum, the present work demonstrates that CB1R deficiency produces changes at the morphological level in the hippocampus, one of the areas involved in learning, memory, and mood regulation. The reduction in the expression of cytoskeletal components of the different hippocampal areas of $\mathrm{CB}_{1} \mathrm{R}^{-/-}$evidences the participation of CB1R in neuronal cytoskeleton consolidation. Morphological and synaptic structure alterations in the CA1 area demonstrate the requirement of CB1R signaling for the correct establishment of synaptic connections. On the whole, the results in the present work provide evidence of the participation of CB1R in neuronal plasticity from a morphological analysis and provide further support for a large number of studies showing CB1R regulation of short- and long-term plasticity.

\section{Declaration of Transparency}

The authors, reviewers and editors affirm that in accordance to the policies set by the Journal of Neuroscience Research, this manuscript presents an accurate and transparent account of the study being reported and that all critical details describing the methods and results are present.

\section{CONFLICT OF INTEREST}

Authors declare no conflict of interest.

\section{AUTHOR CONTRIBUTIONS}

Delia Soriano: Investigation, Methodology, Conceptualization, Formal Analysis, Writing - Original Draft Preparation. Marina Vacotto: Investigation. Alicia Brusco: Conceptualization, Funding Acquisition, Writing - Review \& Editing. Writing - Review \& Editing. Laura Caltana: Conceptualization, Funding Acquisition , Writing Review \& Editing.

\section{PEER REVIEW}

The peer review history for this article is available at https://publo ns.com/publon/10.1002/jnr.24694.

\section{DATA AVAILABILITY STATEMENT}

The data that support the findings of this study are available from the corresponding author upon reasonable request.

\section{ORCID}

Delia Soriano (iD https://orcid.org/0000-0002-3344-3241 Marina Vacotto iD https://orcid.org/0000-0001-5026-7545

Alicia Brusco iD https://orcid.org/0000-0003-4669-3474

Laura Caltana (iD https://orcid.org/0000-0001-5301-4922 


\section{REFERENCES}

Albayram, O., Alferink, J., Pitsch, J., Piyanova, A., Neitzert, K., Poppensieker, K., ... Bilkei-Gorzo, A. (2011). Role of CB1 cannabinoid receptors on GABAergic neurons in brain aging. Proceedings of the National Academy of Sciences of the United States of America, 108(27), 11256-11261.

Alger, B. E. (2009). Endocannabinoid signaling in neural plasticity. In D. Kendall \& S. Alexander (Eds.), Behavioral neurobiology of the endocannabinoid system (pp. 141-172). Berlin, Heidelberg: Springer.

Arellano, J., Benavides-Piccione, R., DeFelipe, J., \& Yuste, R. (2007). Ultrastructure of dendritic spines: Correlation between synaptic and spine morphologies. Frontiers in Neuroscience, 1(1), 131-143.

Arifin, W. N., \& Zahiruddin, W. M. (2017). Sample size calculation in animal studies using resource equation approach. Malaysian Journal of Medical Sciences, 24(5), 101-105.

Aso, E., Renoir, T., Mengod, G., Ledent, C., Hamon, M., Maldonado, R., \& Valverde, O. (2009). Lack of CB1 receptor activity impairs serotonergic negative feedback. Journal of Neurochemistry, 109(3), 935-944.

Bannerman, D. M., Sprengel, R., Sanderson, D. J., McHugh, S. B., Rawlins, J. N. P., Monyer, H., \& Seeburg, P. H. (2014). Hippocampal synaptic plasticity, spatial memory and anxiety. Nature Reviews Neuroscience, 15(3), 181-192.

Barna, I., Zelena, D., Arszovszki, A., \& Ledent, C. (2004). The role of endogenous cannabinoids in the hypothalamo-pituitary-adrenal axis regulation: In vivo and in vitro studies in CB1 receptor knockout mice. Life Sciences, 75(24), 2959-2970.

Bayram-Weston, Z., Olsen, E., Harrison, D., Dunnett, S., \& Brooks, S. (2016). Optimising Golgi-Cox staining for use with perfusion-fixed brain tissue validated in the zQ175 mouse model of Huntington's disease. Journal of Neuroscience Methods, 265, 81-88.

Bilkei-Gorzo, A., Racz, I., Valverde, O., Otto, M., Michel, K., Sastre, M., \& Zimmer, A. (2005). Early age-related cognitive impairment in mice lacking cannabinoid CB1 receptors. Proceedings of the National Academy of Sciences of the United States of America, 102(43), 15670-15675.

Bilkei-Gorzo, A., Albayram, O., Draffehn, A., Michel, K., Piyanova, A., Oppenheimer, H., ... Zimmer, A. (2017). A chronic low dose of $\Delta$ 9tetrahydrocannabinol (THC) restores cognitive function in old mice. Nature Medicine, 23(6), 782-787.

Bohme, G. A., Laville, M., Ledent, C., Parmentier, M., \& Imperato, A. (2000). Enhanced long-term potentiation in mice lacking cannabinoid CB1 receptors. Neuroscience, 95, 5-7.

Botcher, N., Falck, J., Thomson, A., \& Mercer, A. (2014). Distribution of interneurons in the CA2 region of the rat hippocampus. Frontiers in Neuroanatomy, 8, 104.

Bourne, J., \& Harris, K. (2008). Balancing structure and function at hippocampal dendritic spines. Annual Review of Neuroscience, 31, 47-67.

Bowers, M., \& Ressler, K. (2016). Sex-dependence of anxiety-like behavior in cannabinoid receptor 1 (Cnr1) knockout mice. Behavioural Brain Research, 300, 65-69.

Buceta, I., Elezgarai, I., Rico-Barrio, I., Gerrikagoitia, I., Puente, N., \& Grandes, P. (2019). Deletion of the cannabinoid CB1 receptor impacts on the ultrastructure of the cerebellar parallel fiber-Purkinje cell synapses. Journal of Comparative Neurology, 528, 1041-1052.

Burokas, A., Martín-García, E., Gutiérrez-Cuesta, J., Rojas, S., Herance, J. R., Gispert, J. D., ... Maldonado, R. (2014). Relationships between serotonergic and cannabinoid system in depressive-like behavior: A PET study with [11C]-DASB. Journal of Neurochemistry, 130(1), 126-135.

Caltana, L., Saez, T., Aronne, M., \& Brusco, A. (2015). Cannabinoid agonist ACEA improves motor recovery and protects the neurons through activated microglia-induced synaptogenesis in acute phase of ischemic stroke model in mice. Journal of Neurochemistry, 135(3), 616-629.

Candelaria-Cook, F., \& Hamilton, D. (2014). Chronic cannabinoid agonist (WIN 55,212-2) exposure alters hippocampal dentate gyrus spine density in adult rats. Brain Research, 1542, 104-110.
Castillo, P., Younts, T., Chávez, A., \& Hashimotodani, Y. (2012). Endocannabinoid signaling and synaptic function. Neuron, 76(1), 70-81.

Chen, R., Zhang, J., Wu, Y., Wang, D., Feng, G., Tang, Y. P., ... Chen, C. (2012). Monoacylglycerol lipase is a therapeutic target for Alzheimer's disease. Cell Reports, 2(5), 1329-1339.

Chen, F., Bertelsen, A., Holm, I., Nyengaard, J., Rosenberg, R., \& DorphPetersen, K. (2019). Hippocampal volume and cell number in depression, schizophrenia, and suicide subjects. Brain Research, 1727, 146546.

Chevaleyre, V., \& Siegelbaum, S. (2010). Strong CA2 pyramidal neuron synpses define a powerful disynaptic cortico-hippocampal loop. Neuron, 66(4), 560-572.

de Oliveira, A. L., Pasqualini, G. B., Diehl, F., Molina, V. A., \& Quillfeldt, J. A. (2008). Opposite action of hippocampal CB1 receptors in memory reconsolidation and extinction. Neuroscience, 154, 1648-1655.

Dehmelt, L., \& Halpain, S. (2005). The MAP2/Tau family of microtubule-associated proteins. Genome Biology, 6(1), 204.

Díaz-Alonso, J., de Salas-Quiroga, A., Paraíso-Luna, J., García-Rincón, D., Garcez, P. P., Parsons, M., ... Galve-Roperh, I. (2017). Loss of cannabinoid 1 receptors induces cortical migration malformations and increases seizure susceptibility. Cerebral Cortex, 27(11), 5303-5317.

Elphick, M., \& Egertová, M. (2005). The philogenetic distribution and evolutionary origins of endocannabinoids signaling. Handbook of Experimental Pharmacology, 168, 283-297.

Eshkind, L. G., \& Leube, R. E. (1995). Mice lacking synaptophysin reproduce and form typical synaptic vesicles. Cell and Tissue Research, 282(3), 423-433.

Evrard, S., Duhalde-Vega, M., Tagliaferro, P., Mirochnic, S., Caltana, L., \& Brusco, H. (2006). A low chronic ethanol exposure induces morphological changes in the adolescent rat brain that are not fully recovered even after a long abstinence: An immunohistochemical study. Experimental Neurology, 200, 438-459.

Evrard, S., \& Brusco, A. (2011). Ethanol effects on the cytoskeleton of nerve tissue cells. In R.Nixon \& A. Yuan(Eds.), Cytoskeleton of the nervous system (pp. 697-758). New York: Springer. ISBN 1441967869. Cap 29.

Facchinetti, F., Del Giudice, E., Furegato, S., Passarotto, M., \& Leon, A. (2003). Cannabinoids ablate release of TNF alpha in rat microglial cells stimulated with lypopolysaccharide. Glia, 41(2), 161-168.

Fairfield, B., Mammarella, N., Franzago, M., Di Domenico, A., Stuppia, L., $\&$ Gatta, V. (2018). A variant on promoter of the cannabinoid receptor 1 gene (CNR1) moderates the effect of valence on working memory. Memory, 26(2), 260-268.

Fanselow, M., \& Dong, H. (2010). Are the dorsal and ventral hippocampus functionally distinct structures? Neuron, 65(1), 7-19.

Ferreira, S., Teixeira, F., Garção, P., Agostinho, P., Ledent, C., Cortes, L., ... Köfalvi, A. (2012). Presynaptic CB (1) cannabinoid receptors control frontocortical serotonin and glutamate release-Species differences. Neurochemistry International, 61(2), 219-26.

Ferreras, S., Fernández, G., Danelon, V., Pisano, M. V., Masseroni, L., Chapleau, C. A., ... Paglini, M. G. (2017). Cdk5 is essential for amphetamine to increase dendritic spine density in hippocampal pyramidal neurons. Frontiers in Cellular Neuroscience, 11, 372. https://doi. org/10.3389/fncel.2017.00372.

Franklin, K., \& Paxinos, G. (2007). The mouse brain in stereotaxic coordinates (4th ed.). San Diego, CA: Academic Press.

Galve-Roperh, I., Palazuelos, J., Aguado, T., \& Guzman, M. (2009). The endocannabinoid system and the regulation of neural development: Potential implications in psychiatric disorders. European Archives of Psychiatry and Clinical Neuroscience, 259, 371-382.

Garcia-Segura, L., \& Perez-Marquez, J. (2014). A new mathematical function to evaluate neuronal morphology using the Sholl analysis. Journal of Neuroscience Methods, 226, 103-109. 
Gordon-Weeks, P., \& Fournier, A. (2014). Neuronal cytoskeleton in synaptic plasticity and regeneration. Journal of Neurochemistry, 129(2), 206-212.

Gordon, S. L., \& Cousin, M. A. (2016). The iTRAPs: Guardians of synaptic vesicle cargo retrieval during endocytosis. Frontiers in Synaptic Neuroscience, 8, 1.

Gould, E. (2009). Structural plasticity. In P. Andersen, R. Morris, D. Amaral, T. Bliss, \& J. O'Keefe (Eds.), The hippocampus book(pp. 321-342). Oxford: Oxford University Press.

Guadagnoli, T., Caltana, L., Vacotto, M., Gironacci, M., \& Brusco, A. (2016). Direct effects of ethanol on neuronal differentiation: An in vitro analysis of viability and morphology. Brain Research Bulletin, 127, 177-186.

Hay, E., McEwan, A., Wilson, D., Barrett, P., D'Agostino, G., Pertwee, R., \& MacKenzie, A. (2019). Disruption of an enhancer associated with addictive behaviour within the cannabinoid receptor-1 gene suggests a possible role in alcohol intake, cannabinoid response and anxiety-related behaviour. Psychoneuroendocrinology, 109, 104407.

Heifets, B., \& Castillo, P. (2009). Endocannabinoid signaling and longterm synaptic plasticity. Annual Review of Physiology, 71(1), 283-306.

Hillard, C., Weinlander, K., \& Stuhr, K. (2012). Contributions of endocannabinoid signaling to psychiatric disorders in humans: Genetic and biochemical evidence. Neuroscience, 204, 207-229.

Hill, M., Carrier, E., McLaughlin, R., Morrish, A., Meier, S., Hillard, C., \& Gorzalka, B. (2008). Regional alterations in the endocannabinoid system in an animal model of depression: Effects of concurrent antidepressant treatment. Journal of Neurochemistry, 106(6), 2322-2336.

Hill, M., Hillard, C., \& McEwen, B. (2011). Alterations in corticolimbic dendritic morphology and emotional behavior in cannabinoid CB1 receptor-deficient mice parallel the effects of chronic stress. Cerebral Cortex, 21(9), 2056-2064.

Hirvonen, J., Goodwin, R. S., Li, C. T., Terry, G. E., Zoghbi, S. S., Morse, C., ... Innis, R. B. (2012). Reversible and regionally selective downregulation of brain cannabinoid CB1 receptors in chronic daily cannabis smokers. Molecular Psychiatry, 17, 642-649.

Hoffman, A. F., Oz, M., Yang, R., Lichtman, A. H., \& Lupica, C. R. (2007). Opposing actions of chronic 9-tetrahydrocannabinol and cannabinoid antagonists on hippocampal long-term potentiation. Learning \& Memory, 14(1-2), 63-74.

Hu, S., \& Mackie, K. (2015). Distribution of the endocannabinoid system in the central nervous system. Handbook of Experimental Pharmacology, 231, 59-93.

Ilan, A. B., Smith, M. E., \& Gevins, A. (2004). Effects of marijuana on neurophysiological signals of working and episodic memory. Psychopharmacology, 176, 214-222.

Itami, C., Huang, J., Yamasaki, M., Watanabe, M., Lu, H., \& Kimura, F. (2016). Developmental switch in spike timing-dependent plasticity and cannabinoid dependent reorganization of the thalamocortical projection in the barrel cortex. Journal of Neuroscience, 36(26), 7039-7054.

Jackson, S., Pryce, G., Diemel, L., Cuzner, M., \& Baker, D. (2005). Cannabinoid-receptor 1 null mice are susceptible to neurofilament damage and caspase3 activation. Neuroscience, 134(1), 261-268.

Jacob, W., Marsch, R., Marsicano, G., Lutz, B., \& Wotjak, C. T. (2012). Cannabinoid CB1 receptor deficiency increases contextual fear memory under highly aversive conditions and long-term potentiation in vivo. Neurobiology of Learning and Memory, 98, 47-55.

Juhasz, G., Chase, D., Pegg, E., Downey, D., Toth, Z., Stones, K., ... William, D. J. (2009). CNR1 gene is associated with high neuroticism and low agreeableness and interacts with recent negative life events to predict current depressive symptoms. Neuropsychopharmacology, 34(8), 2019-2027.

Jung, S., Lee, S., Chu, K., Park, J., Lee, S., Han, T., \& Kim, M. (2009). Cell proliferation and synaptogenesis in the cerebellum after focal cerebral ischemia. Brain Research, 1284, 180-190.
Karanian, D., Brown, Q., Makriyannis, A., Kosten, T., \& Bahr, B. (2005). Dual modulation of endocannabinoid transport and fatty acid amide hydrolase protects against excitotoxicity. Journal of Neuroscience, 25(34), 7813-7820.

Katona, I., Sperlagh, B., Sık, A., Käfalvi, A., Vizi, E., Mackie, K., \& Freund, T. (1999). Presynaptically located CB1 cannabinoid receptors regulate GABA release from axon terminals of specific hippocampal interneurons. Journal of Neuroscience, 19, 4544-4558.

Kohara, K., Pignatelli, M., Rivest, A. J., Jung, H. Y., Kitamura, T., Suh, J., ... Wickersham, I. R. (2014). Cell type-specific genetic and optogenetic tools reveal novel hippocampal CA2 circuits. Nature Neuroscience, 17(2), 269-279.

Kolb, B., Gorny, G., Limebeer, C., \& Parker, L. (2006). Chronic treatment with $\Delta$-9-tetrahydrocannabinol alters the structure of neurons in the nucleus accumbens shell and medial prefrontal cortex of rats. Synapse, 60(6), 429-436.

Kolb, B., Li, Y., Robinson, T., \& Parker, L. (2018). THC alters alters morphology of neurons in medial prefrontal cortex, orbital prefrontal cortex, and nucleus accumbens and alters the ability of later experience to promote structural plasticity. Synapse, 72(3), e22020.

Kwon, S. E., \& Chapman, E. R. (2011). Synaptophysin regulates the kinetics of synaptic vesicle endocytosis in central neurons. Neuron, 70(5), 847-854.

Lambert, M., \& Fowler, C. (2005). The endocannabinoid system: Drug targets, lead compounds, and potential therapeutic applications. Journal of Medicinal Chemistry, 48, 5059-5087.

Lawston, J., Borella, A., Robinson, J., \& Whitaker-Azmitia, P. (2000). Changes in hippocampal morphology following chronic treatment with the synthetic cannabinoid WIN 55,212-2. Brain Research, 877(2), 407-410.

Lazary, J., Lazary, A., Gonda, X., Benko, A., Molnar, E., Hunyady, L., ... Bagdy, G. (2009). Promoter variants of the cannabinoid receptor 1 gene (CNR1) in interaction with 5-HTTLPR affect the anxious phenotype. American Journal of Medical Genetics Part B: Neuropsychiatric Genetics, 150(8), 1118-1127.

Ledent, C., Valverde, O., Cossu, G., Petitet, F., Aubert, J., Beslot, F., ... Parmentier, M. (1999). Unresponsiveness to cannabinoids and reduced addictive effects of opiates in CB1 receptor knockout mice. Science, 283, 401-404.

Lee, T., Hill, M., \& Lee, F. (2016). Developmental regulation of fear learning and anxiety behavior by endocannabinoids. Genes, Brain and Behavior, 15(1), 108-124.

Lichtman, A. H. (2000). SR 141716A enhances spatial memory as assessed in a radial-arm maze task in rats. European Journal of Pharmacology, 404, 175-179.

Ligresti, A., De Petrocellis, L., \& Di Marzo, V. (2016). From phytocannabinoids to cannabinoid receptors and endocannabinoids: pleiotropic physiological and pathological roles through complex pharmacology. Physiological Reviews, 96(4), 1593-1659.

Lin, Q. S., Yang, Q., Liu, D. D., Sun, Z., Dang, H., Liang, J., ... Li, S. (2011). Hippocampal endocannabinoids play an important role in induction of long-term potentiation and regulation of contextual fear memory formation. Brain Research Bulletin, 86(3-4), 139-145.

Lorenzetti, V., Chye, Y., Silva, P., Solowij, N., \& Roberts, C. (2019). Does regular cannabis use affect neuroanatomy? An updated systematic review and meta-analysis of structural neuroimaging studies. European Archives of Psychiatry and Clinical Neuroscience, 269(1), 59-71.

Maccarrone, M., Valverde, O., Barbaccia, M. L., Castañé, A., Maldonado, R., Ledent, C., ... Finazzi-Agrò, A. (2002). Age-related changes of anandamide metabolism in CB1 cannabinoid receptor knockout mice: Correlation with behaviour. European Journal of Neuroscience, 15(7), 1178-1186.

Marco, E., \& Viveros, M. (2009). Functional role of the endocannabinoid system in emotional homeostasis. Revista de Neurologia, 48(1), 20-26.

Marsicano, G., Wotjak, C. T., Azad, S. C., Bisogno, T., Rammes, G., Cascio, M. G., ... Lutz, B. (2002). The endogenous cannabinoid 
system controls extinction of aversive memories. Nature, 418, 530-534.

Marsicano, G., \& Lafenetre, P. (2009). Roles of the endocannabinoid system in learning and memory. Current Topics in Behavioral Neurosciences, 1, 201-230. https://doi.org/10.1007/978-3-540-88955-7_8.

Martin, M., Ledent, C., Parmentier, M., Maldonado, R., \& Valverde, O. (2002). Involvement of CB1 cannabinoid receptors in emotional behaviour. Psychopharmacology, 159(4), 379-387.

Metna-Laurent, M., \& Marsicano, G. (2015). Risingstars: Modulation of brain functions by astroglial type-1 cannabinoid receptors. Glia, 63 , 353-364.

Mikics, E., Dombi, T., Barsvari, B., Varga, B., Ledent, C., Freund, T., \& Haller, J. (2006). The effects of cannabinoids on contextual conditioned fear in CB1 knockout and CD1 mice. Behavioural Pharmacology, 17, 223-230.

Miller, M., Chadwick, B., Dickstein, D., Purushothaman, I., Egervari, G., Rahman, T., ... Hurd, Y. (2018). Adolescent exposure to $\Delta 9$ tetrahydrocannabinol alters the transcriptional trajectory and dendritic architecture of prefrontal pyramidal neurons. Molecular Psychiatry, 24, 588-600.

Molina-Holgado, E., Arévalo-Martín, A., Vela, J. M., Almazán, G., MolinaHolgado, F., Borrell, J., \& Guaza, C. (2002). Cannabinoids promote oligodendrocyte progenitor survival: Involvement of cannabinoid receptors and phos-phatidylinositol-3 kinase/Aktsignalling. Journal of Neuroscience, 22, 9742-9753.

Monory, K., Polack, M., Remus, A., Lutz, B., \& Korte, M. (2015). Cannabinoid CB1 receptor calibrates excitatory synaptic balance in the mouse hippocampus. Journal of Neuroscience, 35(9), 3842-3850.

Mulder, J., Aguado, T., Keimpema, E., Barabás, K., Ballester Rosado, C., Nguyen, L., ... Harkany, T. (2008). Endocannabinoid signaling controls pyramidal cell specification and long-range axon patterning. Proceedings of the National Academy of Sciences of the United States of America, 105(25), 8760-8765.

Njoo, C., Agarwal, N., Lutz, B., \& Kuner, R. (2015). The cannabinoid receptor CB1 interacts with the WAVE1 complex and plays a role in actin dynamics and structural plasticity in neurons. PLoS Biology, 13(10), e1002286.

Nogueras-Ortiz, C., \& Yudowski, G. A. (2016). The multiple waves of cannabinoid 1 receptor signaling. Molecular Pharmacology, 90(5), 620-626.

Okabe, S. (2007). Molecular anatomy of the postsynaptic density. Molecular and Cellular Neuroscience, 34(4), 503-518.

Oudin, M., Hobbs, C., \& Doherty, P. (2011). DAGL-dependent endocannabinoid signalling: Roles in axonal pathfinding, synaptic plasticity and adult neurogenesis. European Journal of Neuroscience, 34, 1634-1646.

Popov, V. I., Davies, H. A., Rogachevsky, V. V., Patrushev, I. V., Errington, M. L., Gabbott, P. L., ... Stewart, M. G. (2004). Remodelling of synaptic morphology but unchanged synaptic density during late phase long-term potentiation (LTP): A serial section electron micrograph study in the dentate gyrus in the anaesthetized rat. Neuroscience, 128, 251-262.

Quinn, H. R., Matsumoto, I., Callaghan, P. D., Long, L. E., Arnold, J. C., Gunasekaran, N., ... McGregor, I. (2008). Adolescent rats find repeated $\Delta$ 9-THC less aversive than adult rats but display greater residual cognitive deficits and changes in hippocampal protein expression following exposure. Neuropsychopharmacology, 33(5), 1113-1126.

Reich, C. G., Mohammadi, M. H., \& Alger, B. E. (2008). Endocannabinoid modulation of fear responses: Learning and state-dependent performance effects. Journal of Psychopharmacology, 22(7), 769-777.

Renard, J., Vitalis, T., Rame, M., Krebs, M., Lenkei, Z., Le Pen, G., \& Jay, T. (2016). Chronic cannabinoid exposure during adolescence leads to long-term structural and functional changes in the prefrontal cortex. European Neuropsychopharmacology, 26(1), 55-64.
Reynolds, E. (1963). The use of lead citrate at high pH as an electronopaque stain in electron microscopy. Journal of Cell Biology, 17, 208-212.

Rivera, P., Bindila, L., Pastor, A., Pérez-Martín, M., Pavón, F. J., Serrano, A., ... Suárez, J. (2015). Pharmacological blockade of the fatty acid amide hydrolase (FAAH) alters neural proliferation, apoptosis and gliosis in the rat hippocampus, hypothalamus and striatum in a negative energy context. Frontiers in Cellular Neuroscience, 9, 98.

Rotter, A., Bayerlein, K., Hansbauer, M., Weiland, J., Sperling, W., Kornhuber, J., \& Biermann, T. (2013). CB1 and CB2 receptor expression and promoter methylation in patients with cannabis dependence. European Addiction Research, 19(1), 13-20.

Rubino, T., Realini, N., Braida, D., Guidi, S., Capurro, V., Viganò, D., ... Parolaro, D. (2009). Changes in hippocampal morphology and neuroplasticity induced by adolescent THC treatment are associated with cognitive impairment in adulthood. Hippocampus, 19(8), 763-772.

Ruiz-Contreras, A., Delgado-Herrera, M., García-Vaca, P., Almeida-Rosas, G., Soria-Rodríguez, G., Soriano-Bautista, A., ... Vadillo-Ortega, F. (2011). Involvement of the AATn polymorphism of the CNR1 gene in the efficiency of procedural learning in humans. Neuroscience Letters, 494(3), 202-206.

Ruiz-Contreras, A., Carrillo-Sánchez, K., Ortega-Mora, I., Barrera-Tlapa, M., Román-López, T., Rosas-Escobar, C., ... Hernández-Morales, S. (2014). Performance in working memory and attentional control is associated with the rs2180619 SNP in the CNR1 gene. Genes, Brain and Behavior, 13(2), 173-178.

Russell, W. M. S., \& Burch, R. L. (1959). The principles of humane experimental technique. London, UK: Methuen.

Sanchis-Segura, C., Cline, B. H., Marsicano, G., Lutz, B., \& Spanagel, R. (2004). Reduced sensitivity to reward in CB1 knockout mice. Psychopharmacology, 176(2), 223-232.

Schacht, J., Hutchison, K., \& Filbey, F. (2012). Associations between cannabinoid receptor-1 (CNR1) variation and hippocampus and amygdala volumes in heavy cannabis users. Neuropsychopharmacology, 37, 2368-2376.

Schmitt, U., Tanimoto, N., Seeliger, M., Schaeffel, G., \& Leube, R. E. (2009). Detection of behavioral alterations and learning deficits in mice lacking synaptophysin. Neuroscience, 162(2), 234-243.

Schweinsburg, A. D., Brown, S. A., \& Tapert, S. F. (2008). The influence of marijuana use on neurocognitive functioning in adolescents. Current Drug Research Reviews, 1(1), 99-111.

Sholl, D. (1953). Dendritic organization in the neurons of the visual and motor cortices of the cat. Journal of Anatomy, 87, 387-406.

Sim-Selley, L. J. (2003). Regulation of cannabinoid CB1 receptors in the central nervous system by chronic cannabinoids. Critical Reviews in Neurobiology, 15(2), 91-119.

Sim-Selley, L. J., Schechter, N. S., Rorrer, W. K., Dalton, G. D., Hernandez, J., Martin, B. R., \& Selley, D. E. (2006). Prolonged recovery rate of CB1 receptor adaptation after cessation of long-term cannabinoid administration. Molecular Pharmacology, 70(3), 986-996.

Sink, K. S., Segovia, K. N., Collins, L. E., Markus, E. J., Vemuri, V. K., Makriyannis, A., \& Salamone, J. D. (2010). The CB1 inverse agonist AM251, but not the CB1 antagonist AM4113, enhances retention of contextual fear conditioning in rats. Pharmacology, Biochemistry and Behavior, 95(4), 479-484.

Slanina, K., Roberto, M., \& Schweitzer, P. (2005). Endocannabinoids restrict hippocampal long-term potentiation via CB1. Neuropharmacology, 49, 660-668.

Smaga, I., Bystrowska, B., Gawliński, D., Przegaliński, E., \& Filip, M. (2014). The endocannabinoid/endovanilloid system and depression. Current Neuropharmacology, 12(5), 462.

Solowij, N., Stephens, R. S., Roffman, R. A., Babor, T., Kadden, R., Miller, M., ... Vendetti, J. (2002). Cognitive functioning of long-term heavy cannabis users. JAMA, 287, 1123-1132. 
Solymosi, K., \& Köfalvi, A. (2017). Cannabis: A treasure trove or pandora's box? Mini-Reviews in Medicinal Chemistry, 17(13), 1223-1291.

Spilker, C., Nullmeier, S., Grochowska, K., Schumacher, A., Butnaru, I., Macharadze, T., ... Kreutz, M. (2016). A Jacob/Nsmf gene knockout results in hippocampal dysplasia and impaired BDNF signaling in dendritogenesis. PLoS Genetics, 12(3), e1005907.

Steindel, F., Lerner, R., Haring, M., Ruehle, S., Marsicano, G., Lutz, B., \& Monory, K. (2013). Neuron-type specific cannabinoid-mediated G protein signalling in mouse hippocampus. Journal of Neurochemistry, 124, 795-807.

Suárez-Pinilla, P., Roiz-Santiañez, R., de la Foz, V., Guest, P., AyesaArriola, R., Córdova-Palomera, A., ... Crespo-Facorro, B. (2015). Brain structural and clinical changes after first episode psychosis: Focus on cannabinoid receptor 1 polymorphisms. Psychiatry Research: Neuroimaging, 233(2), 112-119.

Tagliaferro, P., Ramos, A., Onaivi, E., Evrard, S., Lujilde, J., \& Brusco, H. (2006). Neuronal cytoskeleton and synaptic densities are altered after a chronic treatment with the cannabinoid receptor agonist WIN 55,212-2. Brain Research, 1085(1), 163-176.

Tahir, S. K., Trogadis, J. E., Stevens, J. K., \& Zimmerman, A. M. (1992). Cytoskeletal organization following cannabinoid treatment in undifferentiated and differentiated PC12 cells. Biochemistry and Cell Biology, 70, 1159-1173.

Tapia, M., Dominguez, A., Zhang, W., del Puerto, A., Ciorraga, M., Benitez, M. J., ... Garrido, J. (2017). Cannabinoid receptors modulate neuronal morphology and ankyring density at the axon initial segment. Frontiers in Cellular Neuroscience, 11, 5.

Tortoriello, G., Morris, C., Alpar, A., Fuzik, J., Shirran, S., Calvigioni, D., ... Courtney, M. (2014). Miswiring the brain: $\Delta 9$-tetrahydrocannabinol disrupts cortical development by inducing an SCG10/stathmin-2 degradation pathway. EMBO Journal, 33(7), 668-685.

Valverde, O., \& Torrens, M. (2012). CB1 receptor-deficient mice as a model for depression. Neuroscience, 204, 193-206.

Villares, J. (2007). Chronic use of marijuana decreases cannabinoid receptor binding and mRNA expression in the human brain. Neuroscience, 145(1), 323-334.

Von Lubitz, D., \& Diemer, N. (1983). Cerebral ischemia in the rat: Ultrastructural and morphometric analysis of synapses in stratum radiatum of the hippocampal CA-1 region. Actaneuropathologica, 61(1), 52-60.

Watson, S., Chambers, D., Hobbs, C., Doherty, P., \& Graham, A. (2008) The endocannabinoid receptor, $\mathrm{CB} 1$, is required for normal axonal growth and fasciculation. Molecular and Cellular Neuroscience, 38, 89-97.

Wilson, R. G., Jr., Tahir, S. K., Mechoulam, R., Zimmerman, S., \& Zimmerman, A. M. (1996). Cannabinoid enantiomer action on the cytoarchitecture. Cell Biology International, 20, 147-157.
Wu, D. F., Yang, L. Q., Goschke, A., Stumm, R., Brandenburg, L. O., Liang, Y. J., ... Koch, T. (2008). Role of receptor internalization in the agonist-induced desensitization of cannabinoid type 1 receptors. Journal of Neurochemistry, 104(4), 1132-1143.

Xu, J., \& Chen, C. (2015). Endocannabinoids in synaptic plasticity and neuroprotection. Neuroscientist, 21(2), 152-168.

Yuan, A., Rao, M., \& Nixon, R. (2012). Neurofilaments at a glance. Journal of Cell Science, 125(14), 3257-3263.

Zhang, P., Ishiguro, H., Ohtsuki, T., Hess, J., Carillo, F., Walther, D., ... Uhl, G. (2004). Human cannabinoid receptor 1: $5^{\prime}$ exons, candidate regulatory regions, polymorphisms, haplotypes and association with polysubstance abuse. Molecular Psychiatry, 9(10), 916-931.

Zimmermann, T., Maroso, M., Beer, A., Baddenhausen, S., Ludewig, S., Fan, W., ... Leschik, J. (2018). Neural stem cell lineage-specific cannabinoid type-1 receptor regulates neurogenesis and plasticity in the adult mouse hippocampus. Cerebral Cortex, 28(12), 4454-4471.

\section{SUPPORTING INFORMATION}

Additional supporting information may be found online in the Supporting Information section.

FIGURE S1 (a) PCR for CB1R and Neo showing diferente genotypes. (b) Western Blot of CB1R, showing no expression in $\mathrm{CB}_{1} \mathrm{R}^{-/-}$. (c) Inmunohistochemistry of CB1R and NeuN showing no expression of $\mathrm{CB} 1 \mathrm{R}$ in neurons in $\mathrm{CB} 1 \mathrm{R}^{-/-}$. (d) Inmunohistochemistry of $\mathrm{CB} 1 \mathrm{R}$ and S100 showing no expression of CB1R in astrocytes in CB1 $\mathrm{R}^{-/-}$

FIGURE S2 Full Blot of NF160 (a), NF200 (b), MAP2 (c) and Syn (d)

TABLE S1 Summary of neuronal changes in hippocampus produced by CB1R deletion

TABLE S2 Summary of synaptic changes in hippocampal CA1 area produced by CB1R deletion

Transparent Science Questionnaire for Authors

Transparent Peer Review Report

How to cite this article: Soriano D, Vacotto M, Brusco A Caltana L. Neuronal and synaptic morphological alterations in the hippocampus of cannabinoid receptor type 1 knockout mice. J Neurosci Res. 2020;00:1-18. https://doi.org/10.1002/ $\underline{\text { jnr.24694 }}$ 